\title{
A DYNAMIC MODEL OF DIFFERENTIAL HUMAN CAPITAL AND CRIMINAL ACTIVITY
}

\author{
H. Naci Mocan \\ Stephen C. Billups \\ Jody Overland \\ Working Paper 7584 \\ http://www.nber.org/papers/w7584 \\ NATIONAL BUREAU OF ECONOMIC RESEARCH \\ 1050 Massachusetts Avenue \\ Cambridge, MA 02138 \\ March 2000
}

The views expressed herein are those of the authors and are not necessarily those of the National Bureau of Economic Research.

(C) 2000 by H. Naci Mocan, Stephen C. Billups, and Jody Overland. All rights reserved. Short sections of text, not to exceed two paragraphs, may be quoted without explicit permission provided that full credit, including (C) notice, is given to the source. 
A Dynamic Model of Differential Human Capital and Criminal Activity

H. Naci Mocan, Stephen C. Billups, and Jody Overland

NBER Working Paper No. 7584

March 2000

JEL No. C61, J24, K42

\begin{abstract}
This paper presents a new, dynamic economic model of criminal activity. Individuals are endowed with legal and criminal human capital. Potential incomes in legal and criminal sectors depend on the level of the relevant human capital, the rate of return, and random shocks. Both types of human capital can be enhanced by participating in the relevant sector. Legal human capital can also be enhanced through savings. Each type of human capital is subject to depreciation. Individuals maximize expected discounted lifetime utility, which depends on consumption. In this two-stage dynamic stochastic model, in each period the individual decides in which sector to participate (legal or illegal), and after the realization of income in that period, he decides on the optimal amount of consumption. A particular decision (e.g. participation in the criminal sector) has implications both for future decisions as well as the choices available to the individual in later periods.

The model allows analyses of the effects of recessions, neighborhood effects, various imprisonment/rehabilitation scenarios, risk aversion, and time preferences on criminal behavior. It provides new insights, which are different from existing models, and it is able to explain the declining propensity of individuals to commit crimes over time.
\end{abstract}

H. Naci Mocan

University of Colorado at Denver

Department of Economics

Campus Box 181, PO Box 173364

Denver, CO 80217-3364

and NBER

nmocan@carbon.cudenver.edu
Stephen C. Billups

University of Colorado at Denver

Department of Mathematics

Campus Box 170, PO Box 173364

Denver, CO 80217-3364

sbillups@carbon.cudenver.edu 


\section{A DYNAMIC MODEL OF DIFFERENTIAL HUMAN CAPITAL AND CRIMINAL ACTIVITY}

\section{Introduction}

Becker's seminal paper (1968) created the foundation for the economic analysis of criminal behavior. Becker's model, extended by Ehrlich (1973), postulates that participation in criminal activity is the result of an optimizing individual's response to incentives such as legal and illegal market opportunities. Rational economic agents decide to engage in criminal activity after comparing the financial rewards from crime to those obtained from legal work, taking into account the probabilities of apprehension and conviction and the severity of punishment. M ore precisely, in the Becker-Ehrlich model the individual maximizes a von N eumann-M orgenstern expected utility function, with arguments of the amount of time devoted to non-market activity (which is fixed), and the consumption of a composite market good. The individual can spend time in both the legal and illegal markets, and the real return (in terms of income or the consumption good) in each market is a monotonically increasing function of time spent in that market. With a subjective probability $p$, the individual is apprehended and punished, which reduces the level of income. With probability (1-p) the individual escapes apprehension and keeps the income generated in both markets. Maximization of expected utility in this framew ork generates a first-order condition, the analysis of which leads to a number of behavioral implications. For example, an increase in the probability of apprehension and the severity of punishment reduces the incentive to participate in criminal activity, and these effects are increasing in the agent's degree of risk aversion. Similarly, a decrease in legal real wages increases the likelihood of criminal activity.

$M$ ore recent models that proposed slight modifications to the Becker-Ehrlich model produce ambiguous comparative static results. For example, Block and Heineke (1975) pointed out that if time spent in legal and illegal activities enter the utility function directly, comparative static analyses cease to yield definitive results under traditional preference restrictions. Schmidt and Witte (1984) showed that in a model consisting of eight possible outcomes, (such as employed and not apprehended; unemployed and not apprehended; unemployed, arrested but not convicted; unemployed, arrested, convicted, and fined; etc.), one cannot determine the relationship between criminal participation and the variables of interest without (in some cases) 
fairly strong assumptions. For example, a negative relationship between time spent in illegal activity and stiffer policing, prosecution, and judicial policies requires the assumption of risk neutrality or decreasing absolute risk aversion with income. The same assumptions are required to establish that the impact of a marginal increase in the gains due to criminal activity on time spent in illegal activity is positive.

The assumption of diminishing absolute risk aversion, which is necessary for meaningful comparative static results in the above cases (and several others), generates counterintuitive results in case of the impact of unemployment on criminal participation. The standard assumption that the individual is risk averse, and that his risk aversion decreases with increasing income, yields the result that an increase in the unemployment rate decreases the time devoted to crime. This counterfactual result emerges in the Schmidt and Witte (1984) model, as well as in similar models, because increased unemployment reduces income, which in turn reduces crime via the decreasing absolute risk aversion assumption that is needed to make other results plausible (Schmidt and Witte 1984, p. 162).

Witte (1980) proposed a model where both time spent in the legal and illegal markets and legal and illegal consumption are arguments of the utility function. Her model too, generates ambiguous comparative static results. Thus, both Block and Heineke (1975) and Witte (1980) conclude that theory alone is insufficient to adequately inform policy decisions, and the guidance of empirical analysis is needed.

Empirical investigations have generally confirmed the predictions of the original Becker-Ehrlich model uncovering negative impacts on crime of deterrence variables and improved economic conditions ${ }^{1}$ (e.g. Corman and Mocan, forthcoming; Freeman and Rodgers 1999; M ocan and Rees 1999; Grogger 1998; Levitt 1997; Tauchen, Witte and Griesinger 1994; Witte 1980, M yers 1983).

A lthough the economic models of crime have revolutionized the analysis of criminal behavior, they have some other potential shortcomings, in addition to the ones described above. For example, they fail to recognize the possibility of a bi-directional causality between criminal activity and its determinants. Although the impact of potential legal earnings (legal wages) on

${ }^{1}$ For a summary of the problems encountered in empirical analyses see Corman and M ocan (forthcoming). 
crime is part of the traditional economic modeling of crime, previous theoretical work fails to take into account the possible influence of criminal activity on future labor market opportunities.

In addition, recently some social scientists have questioned the power and applicability of the economic paradigm to analyze criminal behavior. Some of the explicit or implicit criticisms include the failure to incorporate individual heterogeneity into the model in a satisfactory manner. For example Wilson (1994) stated that "[we need to understand]... that people facing the same incentives often behave in characteristically different ways because they have been habituated to do so," while "changing incentives will not alter the behavior of poorly habituated people as much as we would like, at least in the near term." 2 In other words, differences in individuals' backgrounds, especially with respect to past participation in criminal activity, necessarily impact their response to incentives. Current models fail to address this aspect of heterogeneity. Along the same lines, Dilulio (1996) indicates that urban ethnographers believe that today's crime-prone youngsters are too present oriented for any type of conventional criminal deterrence to work. This implies the difficulty of economics to model and explain the behavior of this new breed of criminal who many believe comprises a significant segment of criminal activity.

In this paper we propose a new economic model of criminal behavior, which addresses these and some other important issues in a coherent framework. The differences between our model and the existing crime models are described in the next section. Section III presents the formal model and its solution. Section IV displays the consumption and the investment policy of the individual whose behavior is analyzed. Section $\mathrm{V}$ presents the dynamic optimal behavior of the individual and responses to various scenarios. Section VI is the conclusion.

\section{Improvements over Previous M odels}

O ur model differs substantially from earlier models cited above and their more recent variants. First, current models of crime are static: individuals make choices at a particular point in time, responding to exogenously determined incentives and given constraints and preferences,

\footnotetext{
${ }^{2}$ Wilson (1994, p.56), as cited by Dilulio (1996)
} 
without regard for the impact of today's decision on future opportunities. ${ }^{3}$ Our model is dynamic and therefore a particular decision (e.g. participation in the criminal sector) has implications both for future decisions as well as the choices available to the individual in later periods. In our model, individuals possess two types of human capital: legal human capital, which determines expected earnings in the legal sector, and criminal human capital, which determines expected illegal earnings. In this setting, the endogenous relationship between differentiated human capital and participation in differentiated labor markets (legal and criminal) is analyzed.

Second, in our model, the individual's earnings (legal as well as illegal) depend on his human capital (legal and illegal), and the rate of return to both types of human capital. In other words, we adopt a standard human capital earnings model, where an exogenous rate of return and endogenous human capital determine the realized earnings (along with stochastic shocks). In this framework we analyze criminal behavior and its evolution in various scenarios, such as a decline in the return to human capital of the individual (maybe due to a negative labor demand shock), and the impact of "neighborhood" or "peer" effects on the acquisition of legal and illegal human capital.

Third, our model not only allows us to analyze the impact of deterrence and legal market opportunities on current criminal activity, it also permits analyses of the nature of the incarceration experience on future behavior. Thus, this is the first paper to propose an analytical approach to the effect of various treatment/punishment regimes on the post-incarceration response of optimizing individuals. In traditional crime models recidivism (repeated criminal behavior) is a rational response to unchanging opportunities faced by the criminal. If it is optimal for the individual to engage in criminal activity given his environment (the return to legal and illegal activities, the cost of punishment and the probability of apprehension) before he went to prison, it will be optimal again after he leaves prison since the relevant constraints remain unchanged. In our model the individual may or may not engage in criminal activity after leaving prison. This is because part of the environment that effects behavior is endogenous and is a function of human capital appreciation or depreciation while in prison.

\footnotetext{
${ }^{3}$ Two exceptions are Flinn (1986) and Lochner (1999). Both of these papers introduce dynamics in some fashion, but they formulate vastly different frameworks than the model we develop in this paper.
} 
Fourth, the dynamic structure of the model enables us to observe multi-period behavior of the individual, which provides additional insights unavailable from static models. For example, first-generation Becker-Ehrlich type crime models predict that an increase in the probability of unemployment in the legal sector, proxied for by an increase in the unemployment rate, increases the likelihood of entry into the illegal sector. These models postulate that this relationship between unemployment and criminal participation is symmetrical; namely, a decrease in unemployment decreases criminal participation. However, the model we propose generates a different and novel prediction. In our model, the potential exists for the individual to participate in the illegal sector during the recession, as predicted by standard theory, but, contrary to the symmetry implied by the standard model, the individual may tend to remain in the criminal sector after the recession ends. This hysteresis, or recession-crime trap, is due to simultaneous depreciation of legal human capital and the appreciation of criminal human capital during the recession: in terms of labor market opportunities, he may not be the same person postrecession.

Fifth, our model is capable of explaining a regularity in criminal activity. As stated by Grogger (1998), " ... [t]he likelihood of committing crime typically increases with age until the late teens and then declines. This relationship is quite robust, and seems to hold up across countries, at different points in time, and largely irrespective of the way crime is measured. Although criminologists have studied this phenomenon extensively, they have yet to explain it (Gottfredson and Hirshi 1986)." Grogger states that "if criminal behavior responds to wages, then the age distribution of crime may well be a labor market phenomenon. Wages represent the opportunity cost of committing crime, and they rise steeply with age during the early part of one's career." (Grogger 1998, p. 757) ${ }^{4}$. Although the rising age-earnings profile of an individual is a reasonable explanation of the decreased propensity to engage in criminal activity as one ages, the actual mechanism and dynamics of this relationship remains unclear. The aforementioned age-earnings profile pertains to legal workers, and not to criminals. The increased age-earnings profile of an individual who has been working in the legal sector is due primarily to the marketable skills acquired through participation in this sector. Therefore, an individual who

4 In a different framework, Leung (1994) shows that in a model with no recidivism the falling segment of the agecrime profile is obtained because a large percentage of offenders are arrested at young ages, and once arrested they 
has participated exclusively in the criminal sector has not accumulated the marketable legal human capital that would provide higher legal wages later in life. An individual who has been participating jointly in both sectors can conceivably increase his human capital over the course of his life cycle to the level where exclusive participation in the legal sector is optimal. However, it is unrealistic to believe that such an individual, one who is presumably employed in a lowskilled/low-wage legal sector job, would have a steep age-earnings profile. Put differently, even though higher wages are expected to deter criminal participation as predicted by standard theory, it is not obvious why a person, who was a criminal at a younger age, and faced a given wage level (presumably lower), should command higher wages in the legal sector when he gets older.

Our benchmark model (explained below) provides a mechanism by which even exclusive participation in the criminal sector throughout an individual's youth can still lead to switching to the legal sector later in life. The mechanism by which this is accomplished is the efficiency with which savings/investment is translated into legal human capital. If a participant in the illegal sector perceives that investment in legal human capital promises a sufficiently high rate of return once he switches to the legal sector, then it may be optimal for him to limit current consumption and save for the future. These savings are then translated into legal human capital via education, and increased legal human capital generates the switch to the legal sector.

We also analyze the impact of risk aversion on criminal activity. For example, the reaction of the present-oriented, low-risk-averse "new breed" of predator to various incentives is investigated. The model also incorporates the concepts of "social capital" and neighborhood effects and investigates their influence on criminal activity, and investigates the response of the individual to a change in risk aversion, which may be due to aging, as well as to a change in the discount rate.

\section{The Benchmark Model.}

The individual maximizes expected discounted lifetime utility, which depends on consumption. There exist two possible income sources, one from participation in the legal sector, and the other from participation in the illegal sector. The individual is endowed with given 
stocks of legal and illegal human capital and inelastically supplies a unit of labor each period. Both types of human capital can be enhanced through investment via savings as well as by acquiring experience in the relevant sector. Both types of human capital are subject to depreciation. Incomes from both legal and illegal sources are functions of the relevant human capitals and their respective rates of return. They are also subject to random shocks.

The individual lives T periods. In each period the individual solves a two-stage dynamic stochastic optimization problem. First the individual decides in which sector to participate (legal or illegal), and after the realization of income in that period, he decides on the optimal amount of consumption. These ideas are formalized as follows.

The individual maximizes

$$
E \sum_{t=0}^{T} \beta^{t} U\left(c_{t}\right)
$$

where $\beta$ is the time discount $(0<\beta<1), c_{t}$ stands for consumption at time $t$, and $E$ is the expectations operator. The utility function $U\left(c_{t}\right)$ depicted in (1) takes on the usual constant relative risk aversion (CRRA) form, where $\sigma$ denotes the coefficient of relative risk aversion.

$$
U\left(c_{t}\right)=\frac{c_{t}^{1-\sigma}}{1-\sigma}
$$

The model does not allow borrowing. Thus, the following holds between consumption $\left(c_{t}\right)$, savings ( $\left.s_{t}\right)$ and income $\left(y_{t}\right)$.

$$
c_{t} \leq y_{t}, s_{t}=y_{t}-c_{t}
$$

The individual is endowed with one unit of labor, which is supplied in either the criminal or legal sector. Income is determined by $y_{t}=\max \left(y^{*}{ }_{t} L_{y}\right)$, where

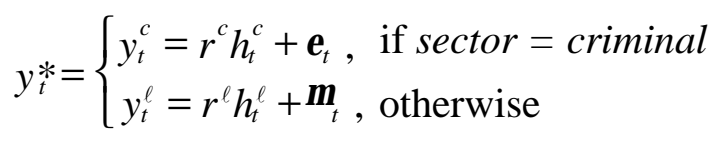

where $L_{y}>0$ represents a lower bound on income, suggesting that welfare programs and other types of social networks provide a positive amount of income to the individual. $y^{c} t$ stands for income from criminal sector at period $t$, and $y^{\prime} t$ represents income from the legal sector at time 
t. $h^{c}$ and $h^{\ell}$ represent criminal and legal human capital, respectively; $r^{c}$ and $r^{\ell}$ stand for the returns to criminal and legal human capitals, respectively, and $\varepsilon$ and $\mu$ are shocks to income with $E[\varepsilon]=0, E[\mu]=0$. We also postulate that $E[\varepsilon \mu]=0$, which indicates that unexpected shocks to legal income (such as a recession) are not correlated with perturbations in illegal income. The shocks have normal distributions with standard deviations $\operatorname{std}(\varepsilon)$ and std $(\mu)$.

Human capital evolves according to the following difference equations.

$$
h_{t+1}^{l}=\Omega+\lambda s_{t}+\left(1-\delta^{l}\right) h_{t}^{l} \quad \text { where } h_{0}^{c} \geq 0, h_{0}^{l} \geq 0 .
$$

Equation ( $5 \mathrm{~A}$ ) indicates that participation in the criminal sector enhances criminal human capital by $\psi$. This means that individuals become more skilled criminals as they acquire criminal experience. According to Equation (5B), participation in the legal sector at time t improves legal human capital by $\Omega$, which suggests that legal human capital is enhanced by labor market experience. Additionally, legal human capital can also be increased by investment, which is equal to savings $\left(\mathrm{s}_{\mathrm{t}}\right)$. In other words, individuals have the option of saving part of their income, and using it to invest in their legal human capital through schooling, training and similar avenues. The notion of investment in human capital is standard (Ben-Porath 1967, Grossman 1972, Becker 1993). On the other hand, the concept of allowing the individual to hold two types of human capital simultaneously within the context of a dynamic crime model has not been explored before. $\lambda$ denotes the efficiency with which legal human capital is acquired. $N$ ote that both forms of human capital are subject to depreciation $\left(\delta^{c}\right.$ and $\left.\delta^{\ell}\right)$.

In this benchmark model the individual makes a discrete decision to participate in either the legal sector or the illegal sector in each period. Put differently, we do not permit (initially) the individual to divide his time between working at the grocery store part-time and committing robberies part-time. The essence of the model is that an optimizing individual makes a decision as to which sector (legal vs. criminal) to participate in at the beginning of each period, and then, over time, he has the option of switching between the two sectors as a response to evolving 
human capital. Nevertheless, as an extension, we also modeled the behavior allowing joint participation in both sectors. The joint strategy (participation in both the legal and criminal sectors) became the optimal choice in very limited cases. Almost always the optimal strategy was to participate in a single sector for a given time period. The results did not change qualitatively under joint participation, and therefore we report the results obtained from the benchmark case presented in Equations (1)-(5).

The stochastic dynamic program described above leads to the following Bellman equation:

$$
\mathrm{E}_{V_{t}}\left(h_{t}^{c}, h_{t}^{\ell}\right)=\max _{0<c<y}\left[U\left(c_{t}\right)+\beta E V_{t+1}\left(h_{t+1}^{c}, h_{t+1}^{\ell}\right)\right] .
$$

This describes the expected value at the present time period of a given combination of human capital stock in terms of optimal participation, consumption, and investment decisions plus the discounted expected value of the resultant human capital combination next period. It is well-known that Equation (6) is equivalent to the maximized value of Equation (1), subject to the appropriate constraints. The problem is too complicated to yield a closed form analytic solution. However, the Bellman equation in (6) can be used as the basis for accurate numerical approximations of policy (optimal sector participation and consumption) for the individual for any period. This is accomplished by working recursively from the end of life (period T) back to period one (similar applications of dynamic programming can be found in Deaton 1992 in the analysis of consumption and savings, and in the unemployment analysis of Gomes, Greenwood and Rebelo 1997). With a suitably large selection of $T$ ( $T>10$ for the range of parameters used in this paper), policy converges to a stationary state, and this permits effective time-series

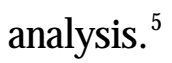

Once the optimal policy is found, we are able to study the behavior of the individual under various regimes including income, punishment, rehabilitation, neighborhood, and preference sets. U sing time-series graphs, we explore the dynamic response of the individual to changes in the relevant parameters.

The estimates of constant relative risk aversion obtained from property/liability insurance and equity pricing analyses range from 1.2 (Szpiro 1986) to 4.0 (Pindyck 1988). In the

\footnotetext{
${ }^{5}$ The basic theory of recursive programming is well presented in Stokey et al. (1989).
} 
benchmark model we set the coefficient of relative risk aversion $(\sigma)$ to 3.0. Empirical estimates of the returns to education suggest that five percent rate of return is a good estimate for the return to legal human capital. Thus, both $r^{c}$ and $r^{\prime}$ set equal to 0.05 in the benchmark specification. Similarly, we specified the following parameters as follows. $L_{y}=10^{-4}, \psi=0.5$, $\Omega=0.1, \lambda=2, \delta^{c}=0.05, \delta^{\prime}=0.05 \sigma=3.0, \beta=0.5, \operatorname{std}(\varepsilon)=0.2, \operatorname{std}(\mu)=0.1$, where std stands for standard deviation of the shocks to income. Notice that the standard deviation of shocks to criminal income is higher than that of legal income, reflecting the assumption that criminal activity is riskier than legal activity. It should also be noted that the results were robust with respect to the selection of these parameter values.

\section{Consumption and Investment Policy}

Figures $1 \mathrm{~A}$ and $1 \mathrm{~B}$ provide a general introduction to the nature of policy generated by the model. In the figures, two pieces of information are put together. The vertical axes display the amount of expected consumption (or investment), and the sign of these consumption and investment values signify the sector in which the individual is participating. Positive values represent participation in the legal sector, and negative values imply criminal activity. Figure $1 \mathrm{~A}$ displays expected consumption policy of the individual in period $T$ as a function of legal and criminal human capital. As the figure demonstrates, when the stock of criminal human capital dominates legal human capital, criminal participation (expected consumption measured on the negative direction) is generated. Relatively high values of legal human capital, on the other hand, are associated with positive consumption values, indicating that the individual is a participant in the legal sector. Figure 1B demonstrates that because the individual is at the end of his life (time $=T$ ) he subscribes to the "you can't take it with you" policy and consumes of all his income (thus, generating zero savings and investment at $\mathrm{T}$ ).

Figures $2 \mathrm{~A}$ and $2 \mathrm{~B}$ display steady state (stationary) consumption and investment policy, respectively, for the benchmark parameters. Note that the consumption values are smaller than those prevailing in period T (F igure 1A) for certain combinations of criminal and legal human capital, because the individual is saving part of his income. Steady state investment (which is equal to savings) is displayed in Figure $2 \mathrm{~B}$. A $\mathrm{s}$ in other figures, Figure $2 \mathrm{~B}$ shows the amount of savings of the individual as well as sector of participation. For example, if the individual has 8 
units of legal human capital and 2 units of criminal human capital, he saves and invests part of his income to enhance his legal capital, and he works in the legal sector (because investment is positive). On the other hand, if criminal capital is equal to 8 units and legal capital is equal to 2 units, the individual is participating in the criminal sector, although he is saving part of his criminal income to increase his legal human capital (this can be seen by the negative value of the investment in Figure 2B when criminal capital $=8$ and legal capital $=2$ ).

The fact that the criminal saves part of his income and invests it to increase his legal human capital captures the essence of the model, and it is an explanation of how individuals who are participating in the criminal sector early in their lives are switching to the legal sector later.

It should be noted that this behavior of investing to legal human capital (even for criminals) is not true under all circumstances. For example, Figures $3 \mathrm{~A}$ and $3 \mathrm{~B}$ present stationary investment policy for two different types of individuals. K eeping all other parameters the same, Figure $3 \mathrm{~A}$ displays the policy of an individual who has low risk aversion $(\sigma=1.3)$, and Figure 3B pertains to an individual who is highly risk averse $(\sigma=6)$. The "new breed of criminal" is typically described as someone with a high level of criminal human capital and low risk aversion. It can be seen in Figure $3 \mathrm{~A}$ that a new breed of "risk-lover" criminal with high criminal human capital and low legal human capital has zero investment to his legal human capital. In fact, such low risk aversion as depicted by $\sigma=1.3$ in Figure 3A makes it optimal for most individuals not to invest in legal human capital. On the other hand, if the person is highly risk averse as depicted by Figure 3B (where $\sigma=6$ ), he saves part of his criminal income, and invests in his legal human capital, even if he is a criminal who possesses a high amount of criminal capital and low legal human capital. Thus, Figures 3A and 3B show how risk aversion impacts the investment in legal human capital, and they indicate that individuals who have low risk aversion and high criminal human capital may not switch to the legal sector as they age.

Figures $4 \mathrm{~A}$ and $4 \mathrm{~B}$ display the stationary investment policy of the individual under the benchmark parameters, in response to variations in the returns to legal and criminal human capital. In Figure 4A the return to criminal human capital, $r^{c}$, is higher than the return to legal human capital, $r^{\prime}\left(r^{c}=0.2\right.$, and $\left.r^{\prime}=0.05\right)$. As a result, investment in legal capital is made only if existing criminal human capital is low. A ccording to Figure $4 \mathrm{~A}$, if the amount of criminal capital is larger than 3 , the individual does not invest anything in his legal capital because of the 
relatively favorable rate of return to criminal human capital in comparison to legal human capital.

Figure 4B displays the investment policy when the rate of return to criminal human capital is 0.05 , but the rate of return to legal human capital is 0.2 . In essence, this graph represents the "carrot and stick" scenario described by Freeman (1996). A low return to criminal human capital can be attributed to effective law enforcement, and a high return to legal capital can be representative of a strong labor market. U nder this scenario, individuals with substantial amounts of criminal human capital have much larger propensity to invest in their legal human capital. The negative investment values in Figure 4B demonstrate the amount of legal human capital investment done by criminals. As can be seen, individuals with large amounts of criminal capital save part of their criminal income and invest in their legal capital. Thus, Figures 4A and $4 \mathrm{~B}$ demonstrate that changes in the returns to legal and criminal human capital can be effective means of influencing criminal activity through their influence on investment in legal capital. This aspect of the model will further be demonstrated in the next section.

Income in legal and criminal sectors depends not only on the respective levels of human capital and the rates of return, but also on the random shocks to income (see Equation 4). A high variance of these shocks signifies increased volatility and is associated with increased risk. For example, if the standard deviation of $\varepsilon$ is high, this suggests that an unexpected large positive shock to criminal income may be followed by an unexpected large negative one. The uncertainly in the perturbations to income influences behavior as depicted by Figures $5 A$ and $5 B$. Stationary investment policy when crime is not risky is displayed in Figure $5 \mathrm{~A}$, where the standard deviation of the shocks to criminal income is only one-third of that for legal income. Here, participants in the legal sector invest most of the earnings to hedge against future risk. In contrast, participants in the criminal sector are unmotivated to invest in their legal capital.

In Figure 5B the standard deviation of illegal income shocks are three times greater than the corresponding shocks in legal income $(\operatorname{std}(\varepsilon)=0.3, \operatorname{std}(\mu)=0.1)$, making it more risky to participate in the criminal sector. Thus, criminals find it optimal to invest in their legal capital. The contrast between Figures $5 A$ and $5 B$ is striking. In Figure 5B, even the individuals who possess very large amounts of criminal capital (who did not invest when the uncertainty of criminal income was smaller than the uncertainty of legal income in Figure $5 \mathrm{~A}$ ) decide to invest 
in their legal human capital as insurance against the relative high uncertainty around the criminal income.

\section{The Dynamic Optimal Behavior}

Figures 6-9 depict the individual's optimal decision path under various scenarios. These figures include the time path of both legal and criminal human capital, and an indicator variable, which represents the sector in which the individual chooses to participate. If the individual chooses the criminal sector, the indicator variable takes the value of -1 ; it is equal to 1 for participation in the legal sector.

\section{A. The Impact of a Recession}

Figure 6 displays the optimal dynamic behavior of the individual before, during and after a recession. The individual's legal human capital is higher than his illegal human capital in period one, and he is a participant in the legal sector. The recession is simulated by imposing five consecutive negative values for $\mu$ (the shock to legal income in Equation 4), starting with time period 2 and ending with period 6 . Given consecutive bad draws of legal income, it would not be surprising to see the individual begin to participate in the criminal sector. Indeed, although the individual still finds it optimal to stay in the legal sector during the first four periods of the recession (periods 2-5), he switches to the criminal sector in period six (the sector indicator switches from +1 to -1 in period 6 ). It is important to note behavior of the human capital during the recession. Between periods 1 and 5 the individual is participating in the legal sector. As a result, his criminal human capital depreciates during that period. However, his legal human capital also depreciates during the same period because of the impact of the recession. N egative income shocks during the recession (negative values of $\mu$ ) reduce his legal income (see Equation 4), which lowers his savings. Even though the legal human capital tends to increase over time because of the experience in the legal sector (depicted by $\Omega$ in Equation $5 B)$, the increase in legal human capital is not large enough to offset the decrease generated by depreciation ( $\delta^{\prime}$ in Equation $5 B$ ). Thus, the net effect of a recession is the decrease in the legal human capital. Starting with period 6 , the individual finds it optimal to switch to the criminal sector. 
The novelty of our dynamic model can be seen in an analysis of human capital and the participation decision after the recession. Participation in the criminal sector during a recession increases the individual's criminal human capital and decreases his legal human capital, which is demonstrated by Figure 6 . The increase in criminal capital and the corresponding decrease in legal capital make it difficult to switch back to the legal sector after the recession is over. In Figure 6, the recession ends in period 7, but the person finds it optimal to stay in the criminal sector after the recession.

The criminal trap, or hysteresis in criminal activity that emerges in our model is in sharp contrast to the predictions of the standard model. The current static crime models posit a symmetry in the pre- and post-recession behavior of the individual: a decrease in legal earnings potential during the recession pulls the individual to crime, and an increase in potential legal earnings after the recession brings him back to the legal sector. By contrast, in our model, as seen in Figure 6, the individual does not switch back to the legal sector after the recession is over: he is not the same person after the recession.

\section{B. Social Capital and Neighborhood Effects}

The concept of social capital has been recently introduced into quantitative analysis of individual behavior. Becker (1996, p.12) states that "[c]onsumption and other activities have a major social component partly because they take place in public. A s a result, people often choose restaurants, neighborhoods, schools, books to read, political opinions, food, or leisure activities with an eye to pleasing peers and others in their social network." The work of Coleman (1990) on social capital, and Becker's article on the impact of others' demands on an individual's own demand (Becker 1991) emphasize the role of social interactions on economic behavior. Becker states that "Since [social] capital captures the effects of the social milieu, an individual's stock of social capital depends not primarily on his own choices, but on the choices of peers in the relevant network of interactions" (Becker 1996, p.12). The impact of peer influence on criminal behavior is stated by Kahan (1998) as "Residents of gang-ridden neighborhoods are not invariably poorer than the residents of relatively gang-free ones. Nor is law-enforcement in gang-ridden neighborhoods invariably laxer. Rather, the difference between these communities lies mainly in attitudes of their residents towards gangs... [p]erceptions 
construct meanings that motivate the decision to join a gang or not. In gang-free neighborhoods, the belief that others value gang membership negatively strengthens the aversion that individual juveniles have toward joining them. But in gang-ridden ones the belief that their peers admire gang members can make joining one seem worthwhile even to juveniles who are otherwise only weakly committed or even opposed to gangs." (Kahan 1998).

To incorporate these ideas and the impact of social capital on behavior, we introduce a "neighborhood effect" into the analysis. A "harmful neighborhood effect" on criminal participation exists if there is high criminal participation in the neighborhood by peers, and therefore it is easier to enhance criminal capital through participation due to this criminal environment, or culture. $M$ ore precisely, in Equation $5 A$, a high value of $\psi$ represents an undesirable peer or neighborhood effect on criminal human capital, while a low value of $\psi$ indicates a low neighborhood effect, where criminal participation does not impact next period's human capital very heavily. Similarly, a low value of $\lambda$ (Equation 5B) can be construed as a harmful neighborhood effect since attempts to acquire legal human capital are hampered.

The contrast between Figures 7A and 7B present the impact of neighborhood effect. To simulate a strong criminal neighborhood effect, $\psi$ is set to $2, \Omega$ is set to zero and $\lambda$ is equal to 0.1 in Figure 7A. On the other hand, a small criminal neighborhood effect is simulated in Figure 7B by setting $\psi$ to $0.1, \Omega$ to 0.2 , and $\lambda$ to 2 .

In Figure 7A the individual is participating in the legal sector initially. The disincentive to invest in legal human capital (low $\lambda$ and $\Omega$ ), and the efficiency with which criminal capital is acquired (high $\psi$ ) motivates him to switch to, and stay in the criminal sector after period 5 . On the other hand, Figure 7B shows that despite that fact the individual has substantially more criminal human capital in the beginning, and therefore a participant of the criminal sector, the low neighborhood effect makes it optimal to switch to the legal sector. He invests in his legal human capital, increasing it from period 1 to period 2 . The same is true for periods 2 and 3 , and he switches to the legal sector in period 4.

\section{Imprisonment}

The potential importance of rehabilitation on post-prison behavior is acknowledged by researchers as well as members of the criminal justice system. Administrators of the California 
and Federal prison systems indicated that "... rehabilitation programming was being made available... to provide the opportunities and experiences to enable individuals in less destructive, more socially acceptable ways" (California Department of Correction, 1978, V ol II, p. 8 as cited by Witte 1983). Unlike previous economic models of crime, our model allows the investigation of the impact of various imprisonment scenarios on post-incarceration behavior. Imprisonment is simulated as a period during which the income of the inmate is constant and set to a low (subsistence) level in Equation 4. Low income does not allow savings and investment. The impact of the prison term on post-period criminal activity is analyzed by investigating the influence of rehabilitation and prison culture. In this analysis, in Equations $5 \mathrm{~A}$ and $5 \mathrm{~B} \psi$ and $\Omega$ stand for the impact of the prison culture and rehabilitation, respectively. M ore precisely, if $\psi>0$ this means that the prison culture enhances criminal human capital. If $\Omega>0$ this suggests that the prison provides education, job training and other legal human capital enhancing skills, which we will call rehabilitation. While in prison, both types of human capital depreciate (see Equations $5 \mathrm{~A}$ and $5 \mathrm{~B}$ ). The post-prison activity of the individual in general depends on how fast both types of human capital depreciate in relation to each other, as well as the magnitudes of the rehabilitation $(\Omega)$, and prison culture $(\psi)$.

In the simulations we perform, we impose a 5-period prison term on an individual who al ready decided to participate in the criminal sector. In this framework, we investigate how different regimes impact the post-prison behavior. Figure $8 \mathrm{~A}$ is the benchmark case where the time-series behaviors of both legal and criminal human capital, as well as sector choice are displayed. As can be seen from Figure $8 \mathrm{~A}$, the indicator variable is -1 everywhere, indicating that the individual finds it optimal to be a criminal.

Figures 8B-8D display the simulations based on various imprisonment regimes for the same individual depicted in Figure $8 \mathrm{~A}$. In Figure $8 \mathrm{~B}$ there is no rehabilitation or prison culture $(\psi=\Omega=0)$. The person participates in the criminal sector in period 1, goes to prison between periods 2 and 6 . He finds it optimal to go back to the criminal sector for the periods 7-9, during which time he invests in his legal human capital, and switches to the legal sector in period 10.

Figure $8 \mathrm{C}$ portrays the same individual as in Figure 8A and 8B. However, this time the individual is exposed to a strong prison culture, which enhances his criminal human capital $(\psi=1)$. This takes place through learning from other inmates. In the simulation that 
generated Figure $8 \mathrm{C}$ it is also assumed that the prison does not provide enhancement to the legal capital $(\Omega=0)$. In this case, the criminal human capital of the inmate appreciates, and his legal human capital depreciates while in prison, and when he leaves the prison in period 7, he is a better criminal than before (with more criminal human capital). Thus he finds it optimal to participate in the criminal sector after leaving the prison, and he stays in the criminal sector thereafter.

Figure 8D displays the impact of a strong rehabilitation regime while in prison between periods 2 and 6. In particular, the impact of the prison culture is eliminated ( $\psi$ is set to zero), and it is assumed that legal human capital appreciates through rehabilitation and training while prison $(\Omega=1)$. Under these conditions, the criminal human capital of the person declines while in prison, while his legal human capital increases. As a result, when he leaves the prison in period 7 , he finds it optimal to participate in the legal sector.

\section{Reactions to the Severity of Punishment}

Following the standard practice in the Becker-Ehrlich tradition of expressing sanctions in monetary terms, variations in illegal income can be attributed to variations in law

enforcement. Variations in the return to illegal human capital $\left(\mathrm{r}^{\mathrm{c}}\right)$ provide a convenient means by which to model the effects of the severity of punishment and its impact on sectoral participation. For example, a decrease in the returns to criminal capital may represent an increase in the severity of punishment as a given amount of criminal human capital is generating a lower level of income than before.

Figure 9B displays the dynamic reaction of the individual to an increased severity of punishment in comparison to the benchmark case displayed in Figure 9A. In Figure 9A, the return to criminal human capital is 0.1. The individual depicted in Figure 9A chooses to be a criminal in period 1, does not invest in his legal human capital, and stays a criminal for the remaining time periods. In Figure 9B we observe his behavior in response to an decrease in the return to criminal human capital (a decline in $r^{c}$ to 0.02 ). After participating in the criminal sector in periods 1,2 , and 3 and investing in his legal human capital during the same period, he switches to the legal sector in period 4, and finds it optimal be to in the legal sector 
thereafter.

\section{E. Changes in Risk Aversion}

Previous sub-sections demonstrated how the individual reacts to changes in the returns to criminal activity, to the neighborhood effects, to the rehabilitation in the prison, and to a recession by switching between criminal and legal sectors over time. A nother way the individual may switch between sectors is due to a change in his risk aversion. A lthough the risk aversion parameter $(\sigma)$ is exogenous in the model, it is conceivable that it can increase over time. This may simply reflect the possibility that the individual becomes more risk averse as he gets older. There exists empirical evidence on a positive relationship between age and risk aversion (e.g. Jianakoplos and Bernasek 1998, Palsson 1996).

Figure 10 demonstrates the optimal behavior of the individual when his risk aversion increases. The individual is a criminal in periods 1-4. As a result, his criminal human capital is rising and his legal human capital is declining over this period. In period 5 risk aversion parameter $(\sigma)$ rises from 1.3 to 6 . Because of this change, the individual starts investing more heavily in his legal human capital, which generates a net increase in his legal human capital. A lthough it is still optimal to be a criminal in periods 5, 6, and 7, the individual switches to the legal sector in period 8 . Thus, consistent with Figures $3 \mathrm{~A}$ and $3 \mathrm{~B}$, an increase in risk aversion generates increased investment in legal capital, which eventually yields a switch to the legal sector. This is another avenue through which criminals can switch to the legal sector over time.

\section{F. Changes in Time Preference}

Becker and M urphy (1988) show that persons with high discount rates for the future are more likely to participate in addictive behaviors. Becker, Grossman and M urphy (1991) show that more educated people are more future oriented, which suggests a positive correlation between education and time discount. As summarized by Grossman (2000), and Becker (1996), the standard practice in economics is to assume that the time discount rate on future utility is constant for an individual, although it may differ across individuals. Furthermore, it is assumed that the causality runs from time preference to schooling. A recent paper by Becker and M ulligan (1997) postulates that the present value of utility is higher, the smaller the rate of time preference for the present $[\beta=1 /(1+g)$, where $g$ is the rate of time preference for the present]. Thus, individuals have incentives to make investments that lower the rate of time preference for 
the present. Becker and M ulligan show that the rate of time preference falls as the level of education rises, because education increases income and life expectancy. Thus, following Becker and M ulligan (1997) it can be argued that as individuals invest in their legal human capital their rate of time preference goes down, indicating an increase in $\beta$.

Figure 11 demonstrates the impact of the increase in $\beta$. The individual depicted in Figure 11 participates in the criminal sector from period 1 to 5 . His criminal human capital is higher than his legal human capital. C Criminal human capital is increasing during this period because of participation in the criminal sector. Legal human capital is rising also, because of savings. In periods $1-5 \beta=0.4$. In period 5 we increased $\beta$ to 0.6 in order to reflect the Becker-M ulligan scenario of changing time discount due to increased education. As Figure 11 shows, the result is a switch to the legal sector in period 6 . Thus, this exercise demonstrates that a change in time preference is also capable to generating a switch between criminal and legal sectors in this model.

\section{Conclusion}

This paper presents a new economic model of criminal activity. Individuals possess two types of human capital: legal and criminal. Criminal human capital can be enhanced by participating in criminal activity. Legal human capital can be enhanced by working in the legal sector, or by schooling (by saving part of the income-legal or criminal, and investing it to legal capital). Each type of human capital is subject to depreciation. Potential income in each sector depends on the level of the human capital, the relevant rate of return, and random shocks. In this two-stage dynamic stochastic model, in each period the individual decides in which sector to participate (legal or illegal), and after the realization of income in that period, he decides on the optimal amount of consumption.

The endogenous relationship between differentiated human capital and differentiated labor markets (legal and criminal) renders the individual's labor market opportunities endogenous. The choices made in each period influence the opportunities available in future periods.

The model provides a framework in which the interplay between criminal participation, legal market earnings, and deterrence can be analyzed. Thus, for the first time in a consistent intertemporal model, the analysis of the effects of recessions, 
neighborhood effects, various imprisonment/rehabilitation scenarios, risk aversion, and time preferences on criminal behavior is possible.

Several critically important issues in the analysis of criminal behavior remain unresolved due to the time-dependant nature of the problems-but are effectively addressed in our model. For example, our model allows an analytical approach to the effect of various treatment/punishment regimes on the post-incarceration response of optimizing individuals. In traditional crime models, recidivism is a rational response to unchanging opportunities faced by the criminal. If it is optimal for the individual to engage in criminal activity before he went to prison, it will still be optimal after he leaves prison if the environment remains unchanged. In our model the individual may or may not engage in criminal activity after leaving prison. This is because part of the environment that affects behavior is endogenous and is a function of the appreciationdepreciation of human capital while in prison.

The model generates some new insights, which are different from those provided by static models. For example, Becker-Ehrlich type crime models predict that an increase in the probability of unemployment in the legal sector, represented by an increase in the unemployment rate, increases the likelihood of entry into the illegal sector. These models postulate that this relationship between unemployment and criminal participation is symmetrical; namely, a decrease in unemployment decreases criminal participation. In our model, the potential exists for the individual to find it optimal to participate in the illegal sector during the recession, as predicted by standard theory; but, contrary to the symmetry implied by the standard model, the individual may tend to remain in the criminal sector after the recession ends. This is due to simultaneous depreciation of legal human capital and the appreciation of criminal human capital during the recession.

The model is capable of explaining a regularity in criminal activity, which is the reduced propensity of an individual to engage in criminal activity as he/she ages. A switch from the criminal sector to the legal sector can be optimal in a number of ways. First, criminals may find it optimal to acquire legal human capital as a hedge against the uncertainty around criminal income. The investment in legal human capital while being a criminal is a primary endogenous 
mechanism which makes the decision to switch to the legal sector optimal. Exogenous channels which may create the same behavior include changes in time preference (due to education) and changes in risk aversion (due to aging).

The model also incorporates the concepts of social capital and neighborhood effects and investigates their influence on criminal activity. Similarly, the impact of a decrease in the return to criminal capital (which represents increased severity of punishment) on criminal activity is analyzed. 
Figure 1A: Consumption Policy $($ Time $=T)$

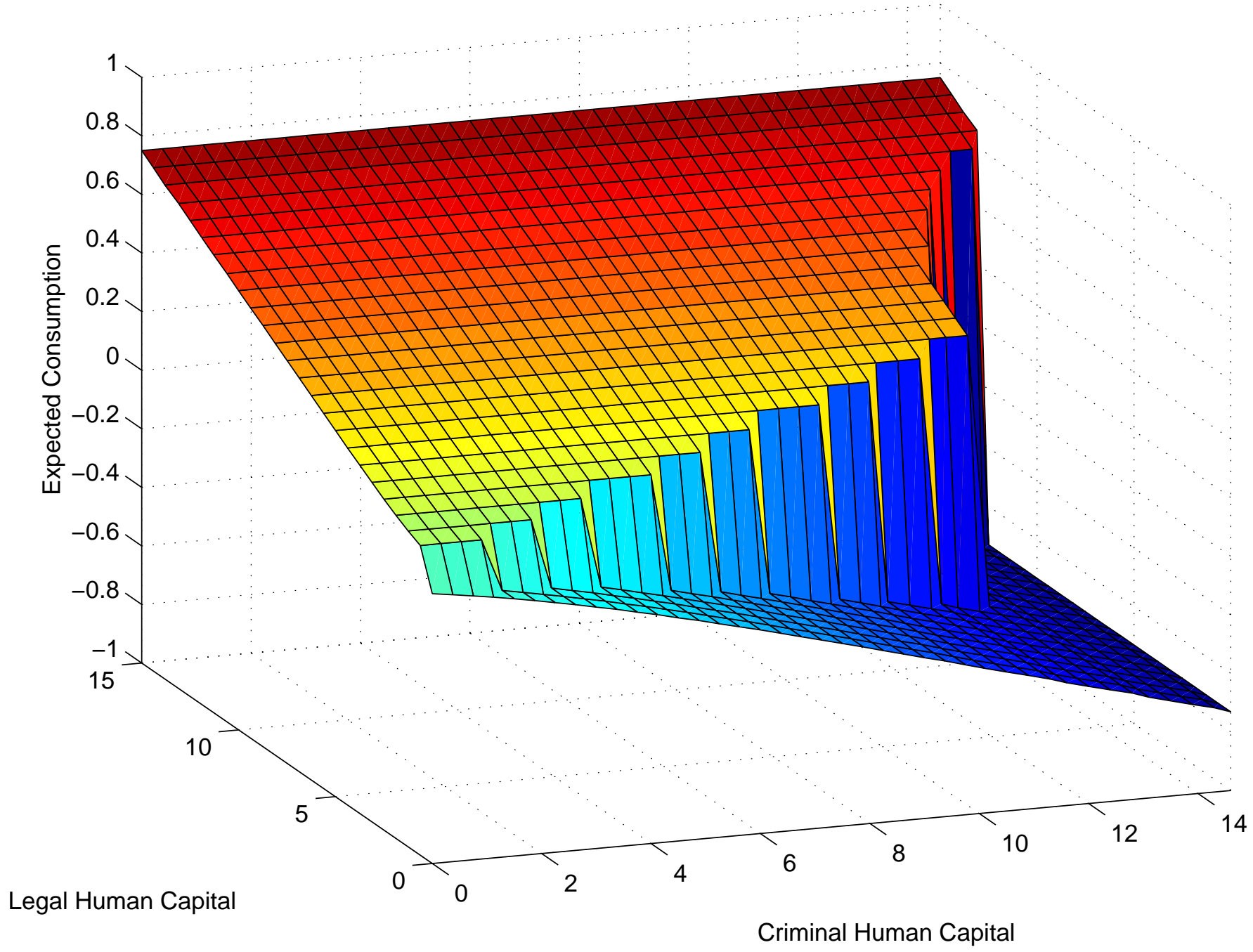


Figure 1B: Investment Policy $($ Time $=T)$

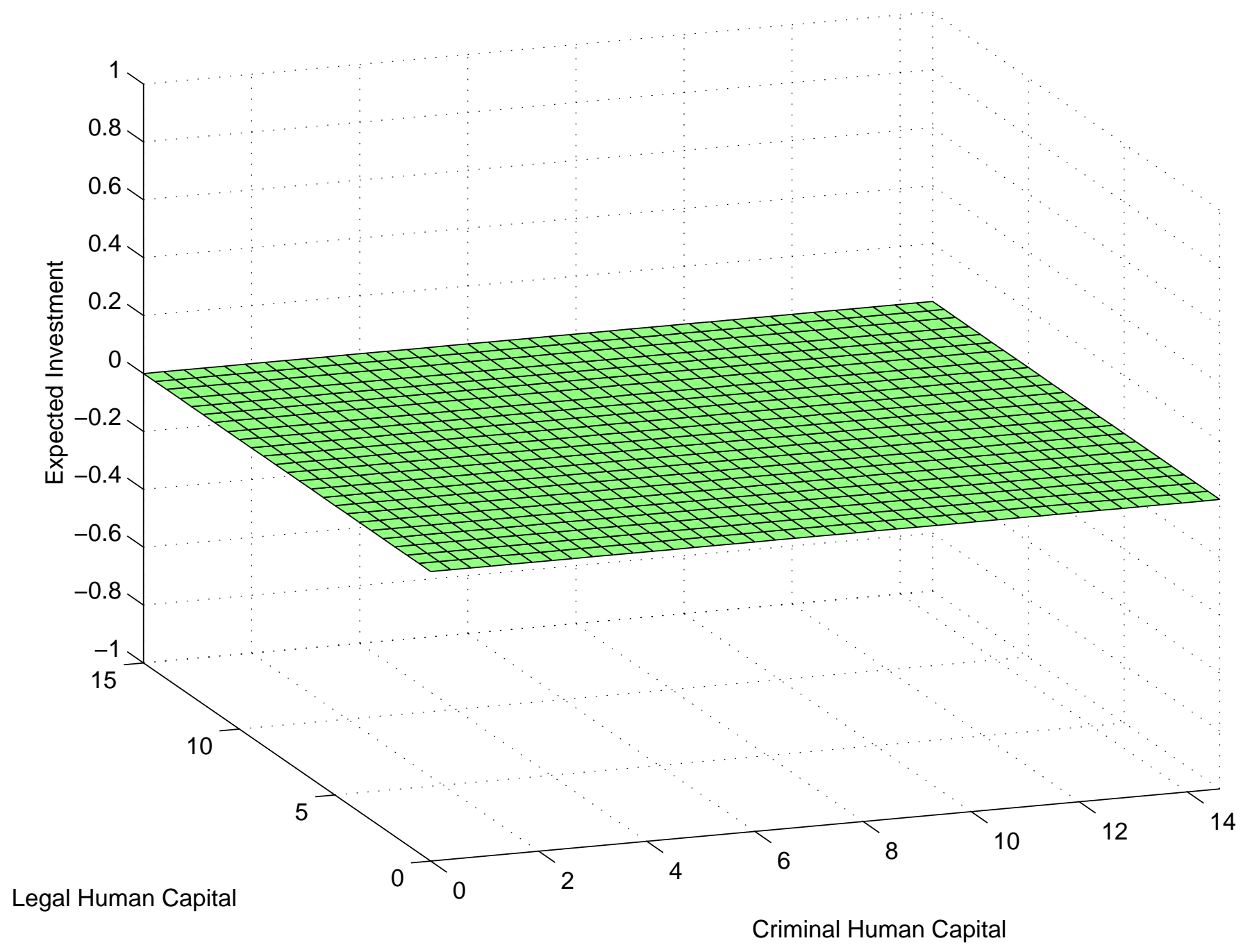


Figure 2A: Consumption Policy (Steady State)

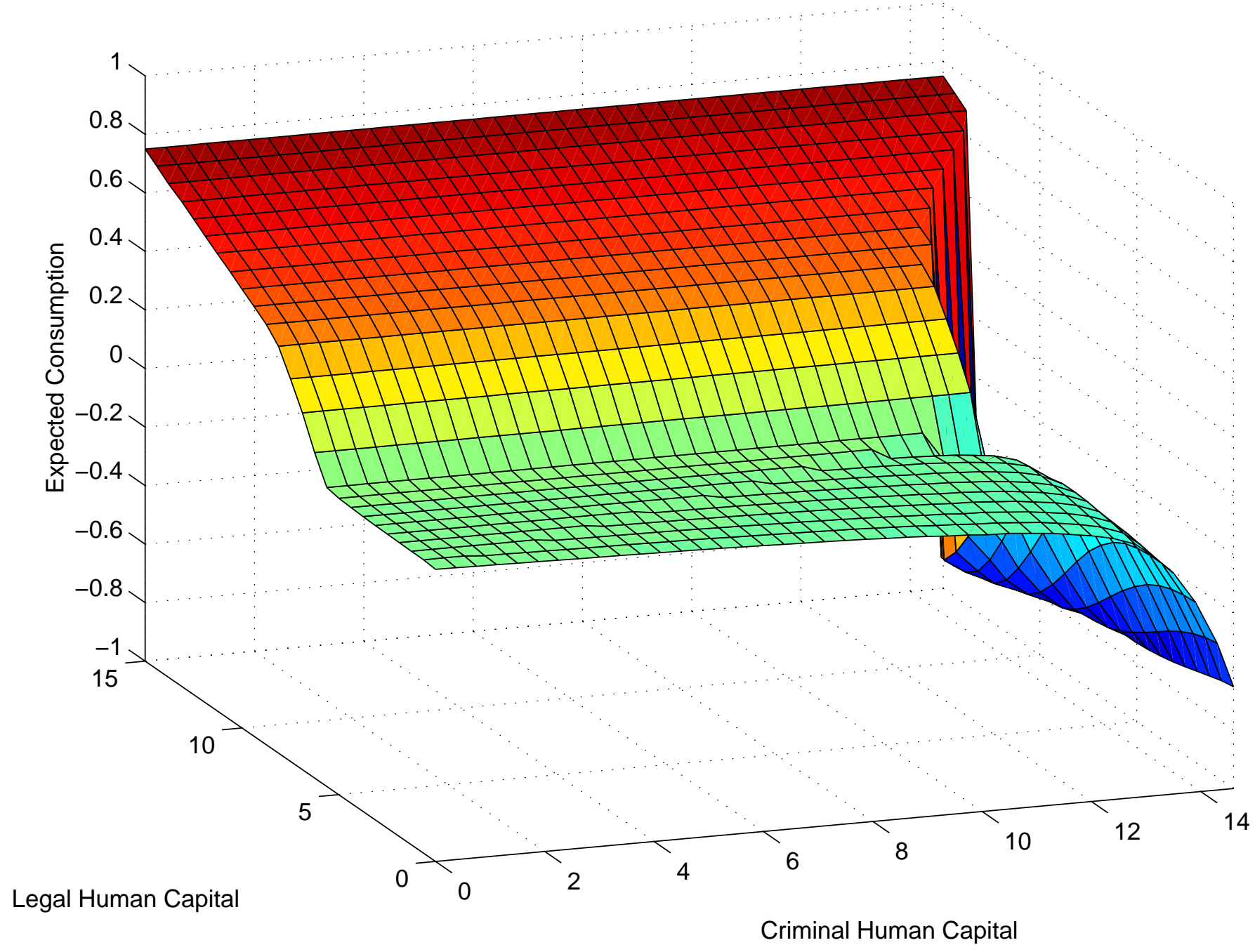


Figure 2B: Investment Policy (Steady State)

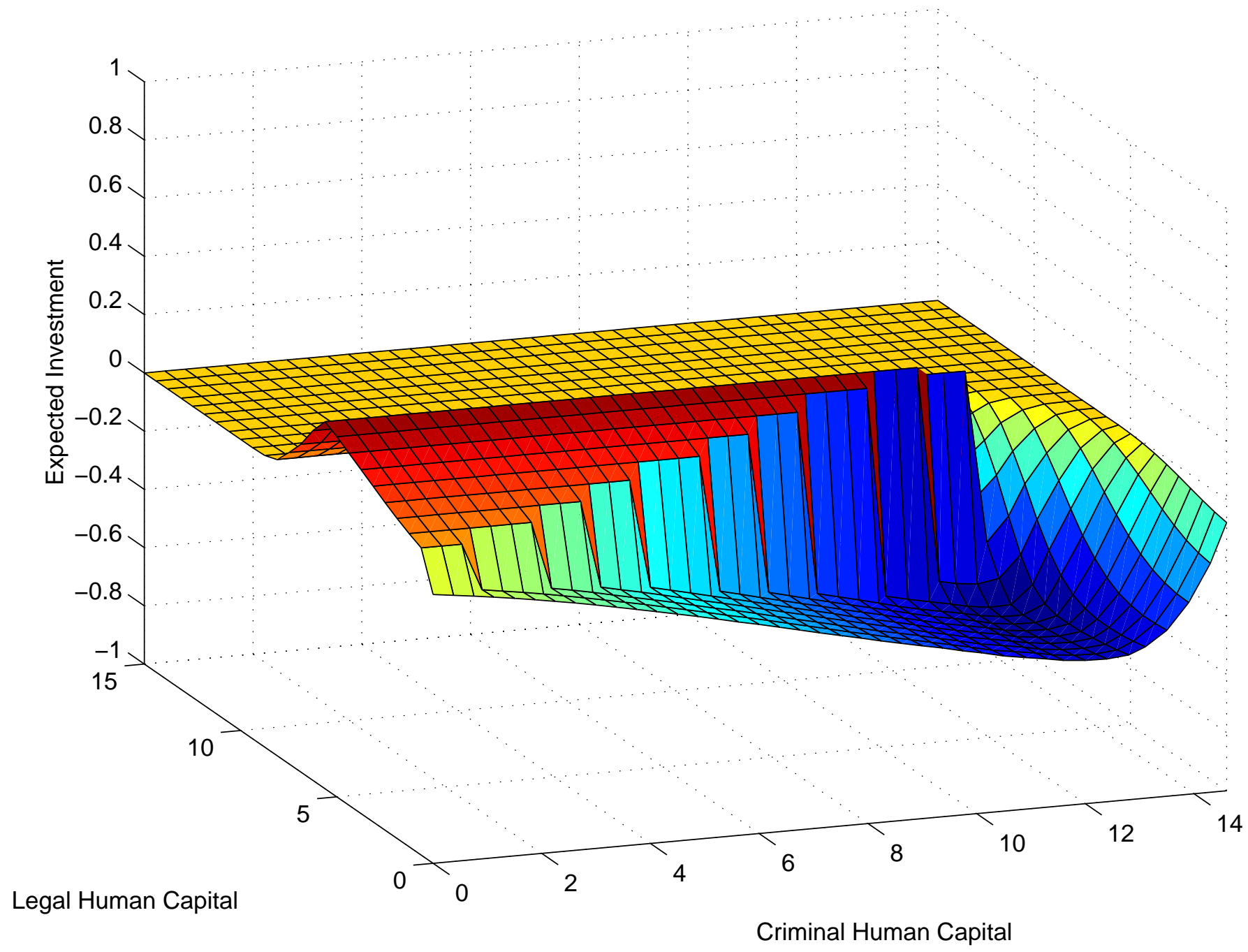


Figure 3A: Investment Policy $\sigma=1.3$

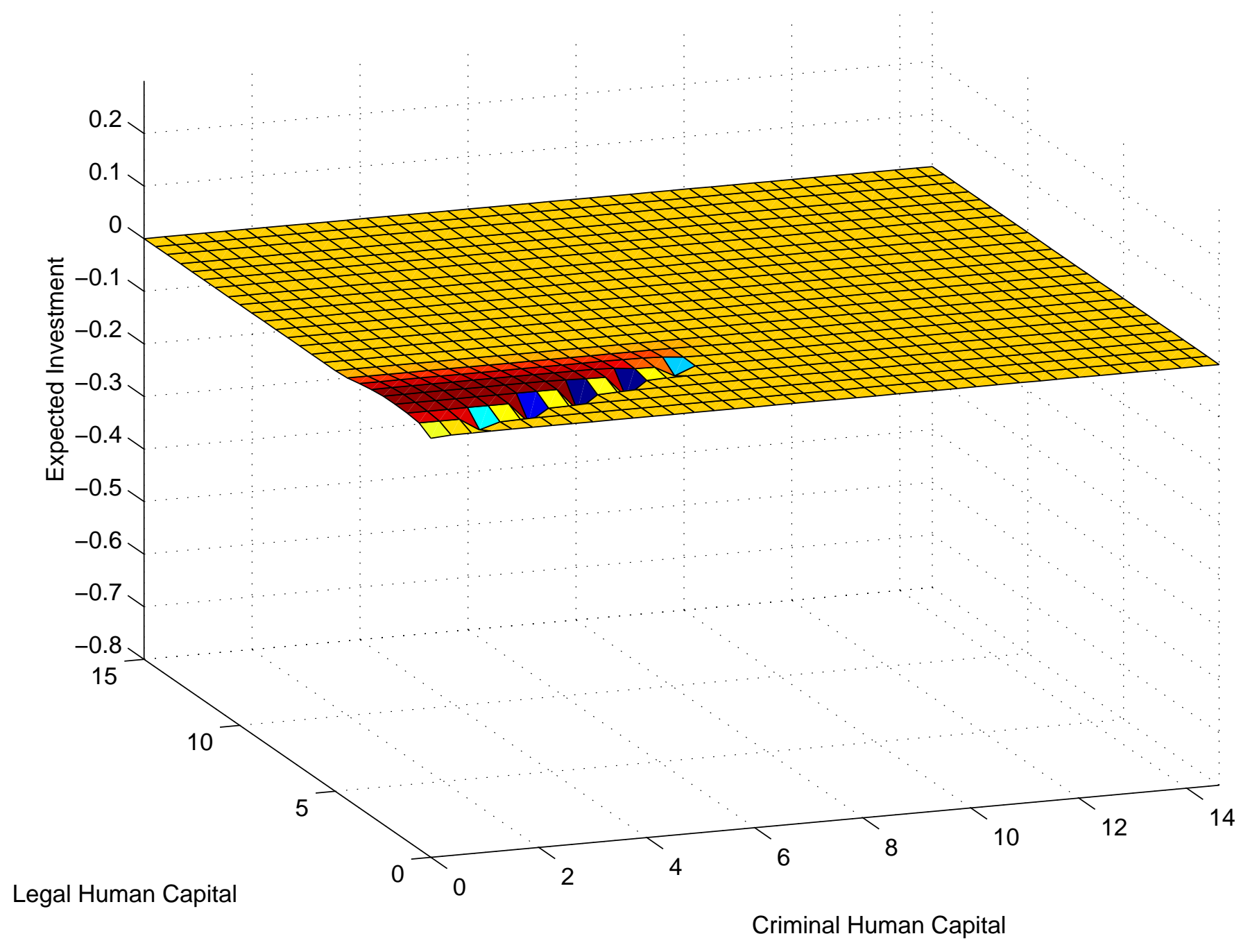


Figure 3B: Investment Policy $\sigma=6$

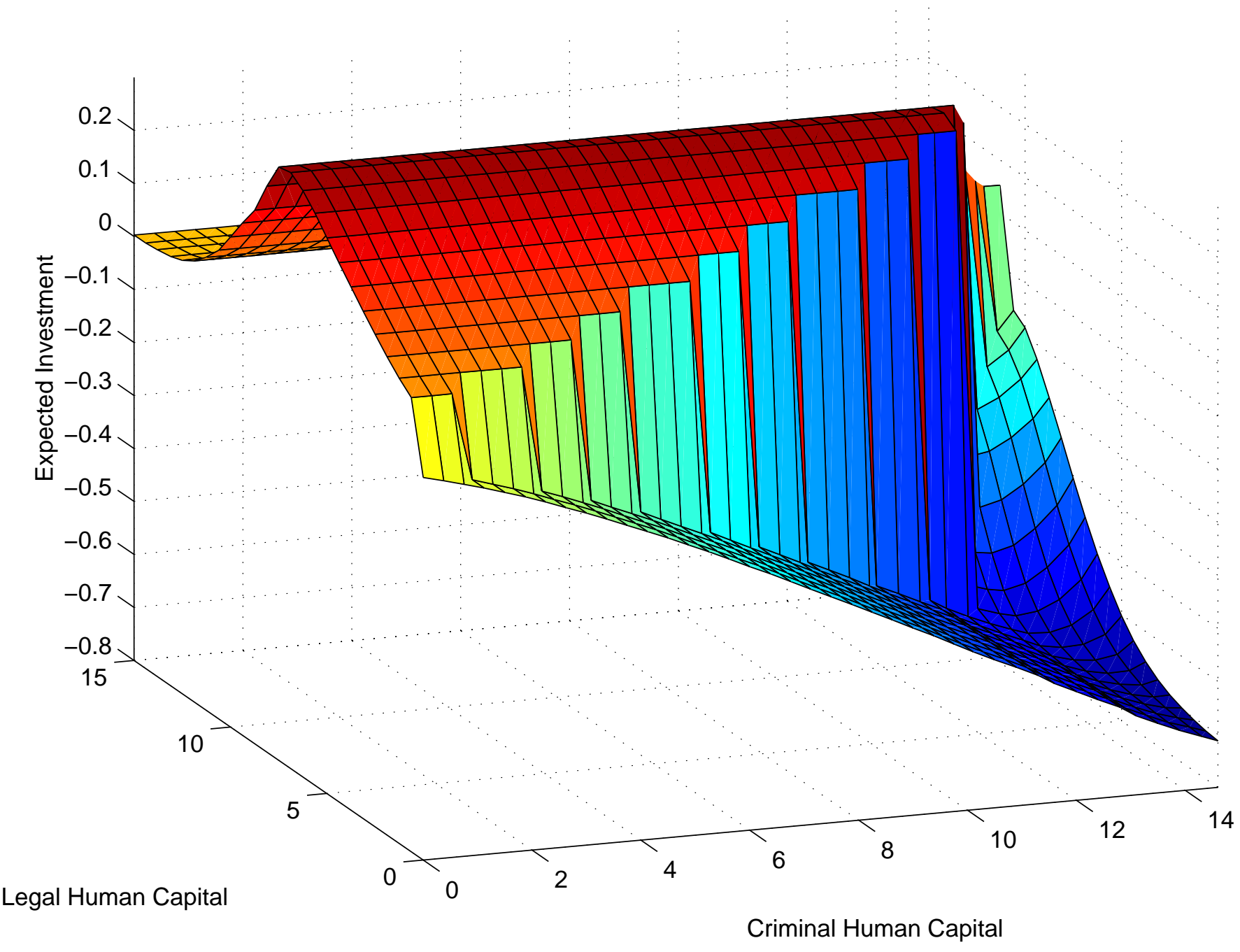


Figure 4A: Investment Policy $r^{c}=0.2, r^{\ell}=0.05$

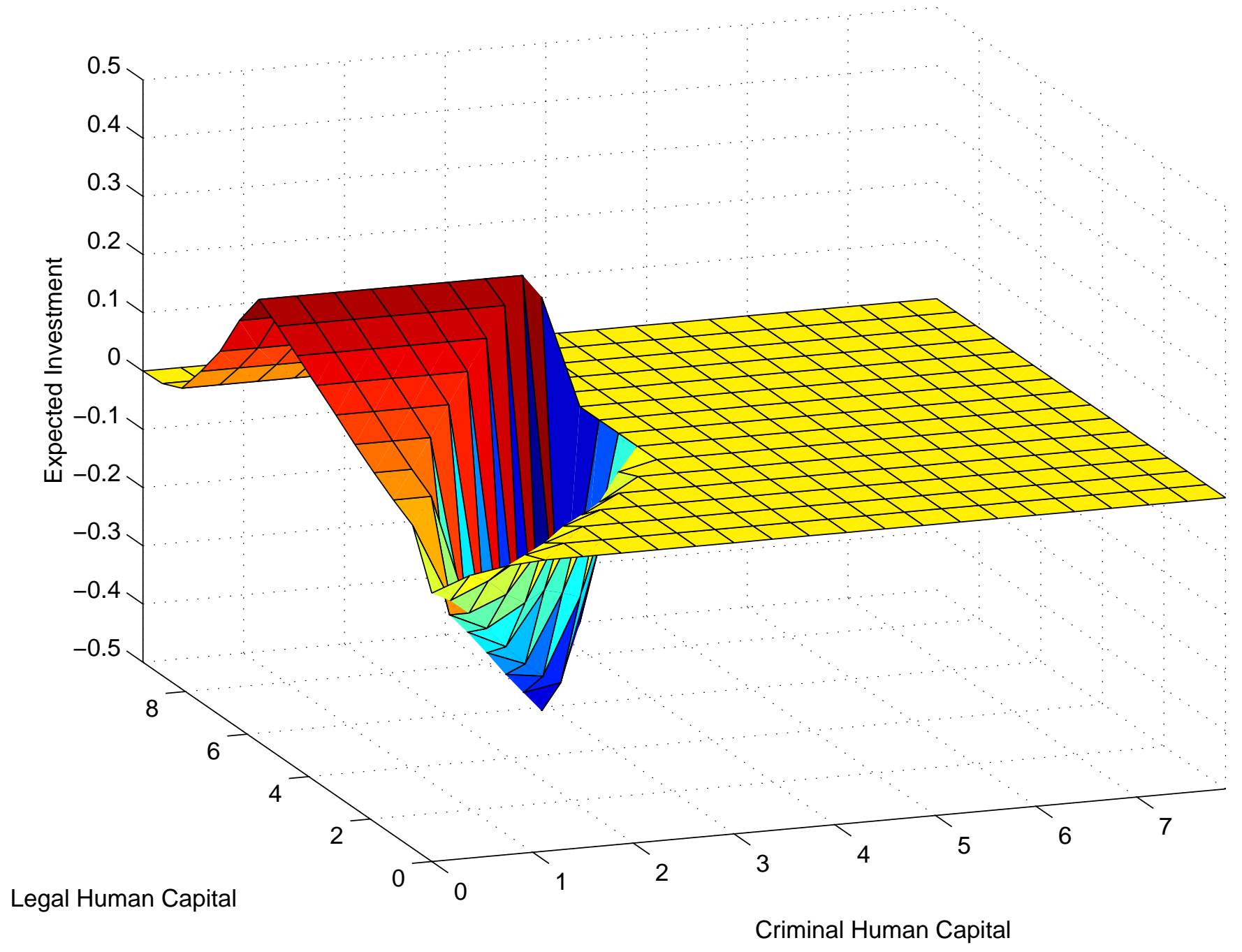


Figure 4B: Investment Policy $r^{c}=0.05, r^{\ell}=0.2$

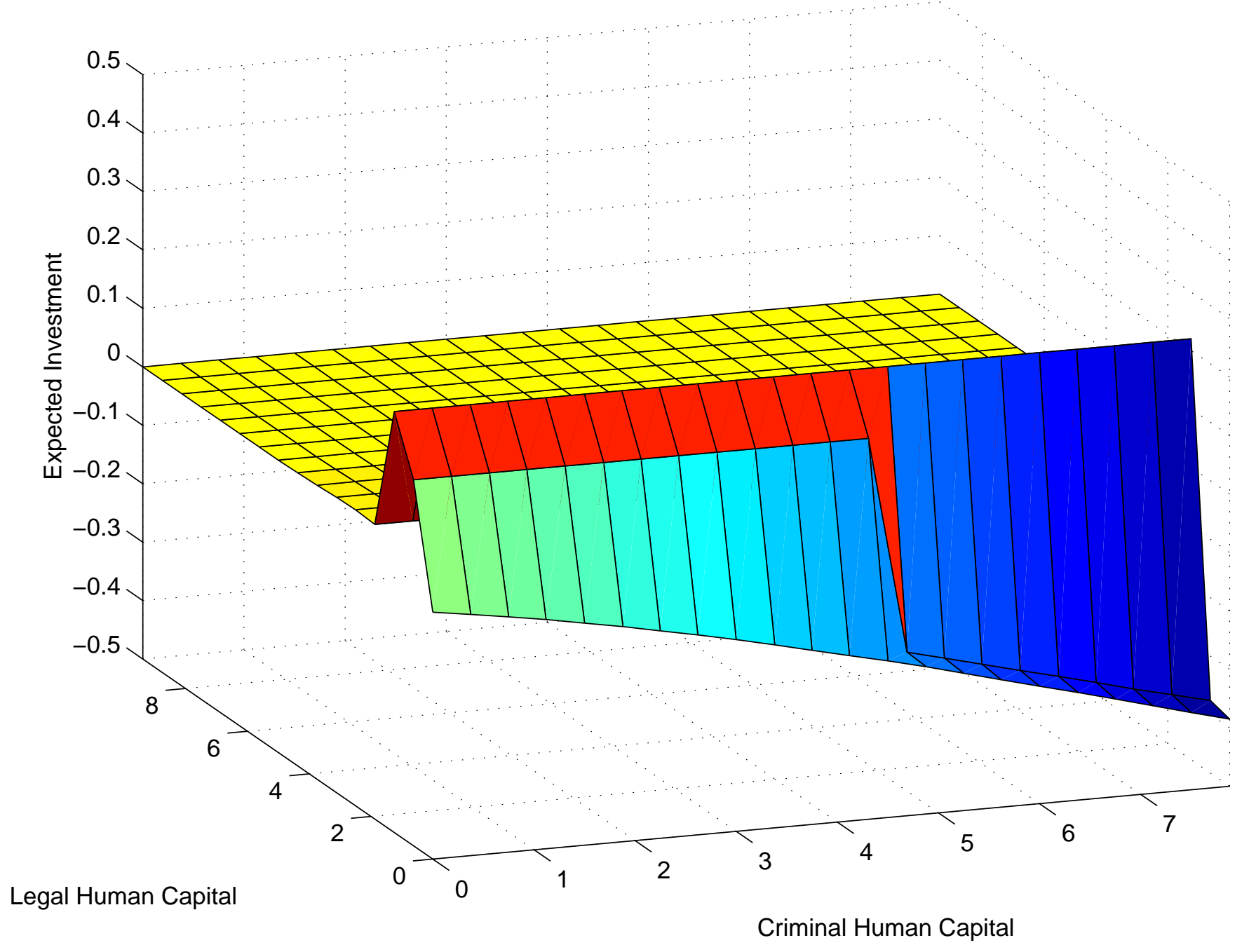


Figure 5A: Investment Policy $\operatorname{Std}(\epsilon)=0.1, \operatorname{Std}(\mu)=0.3$

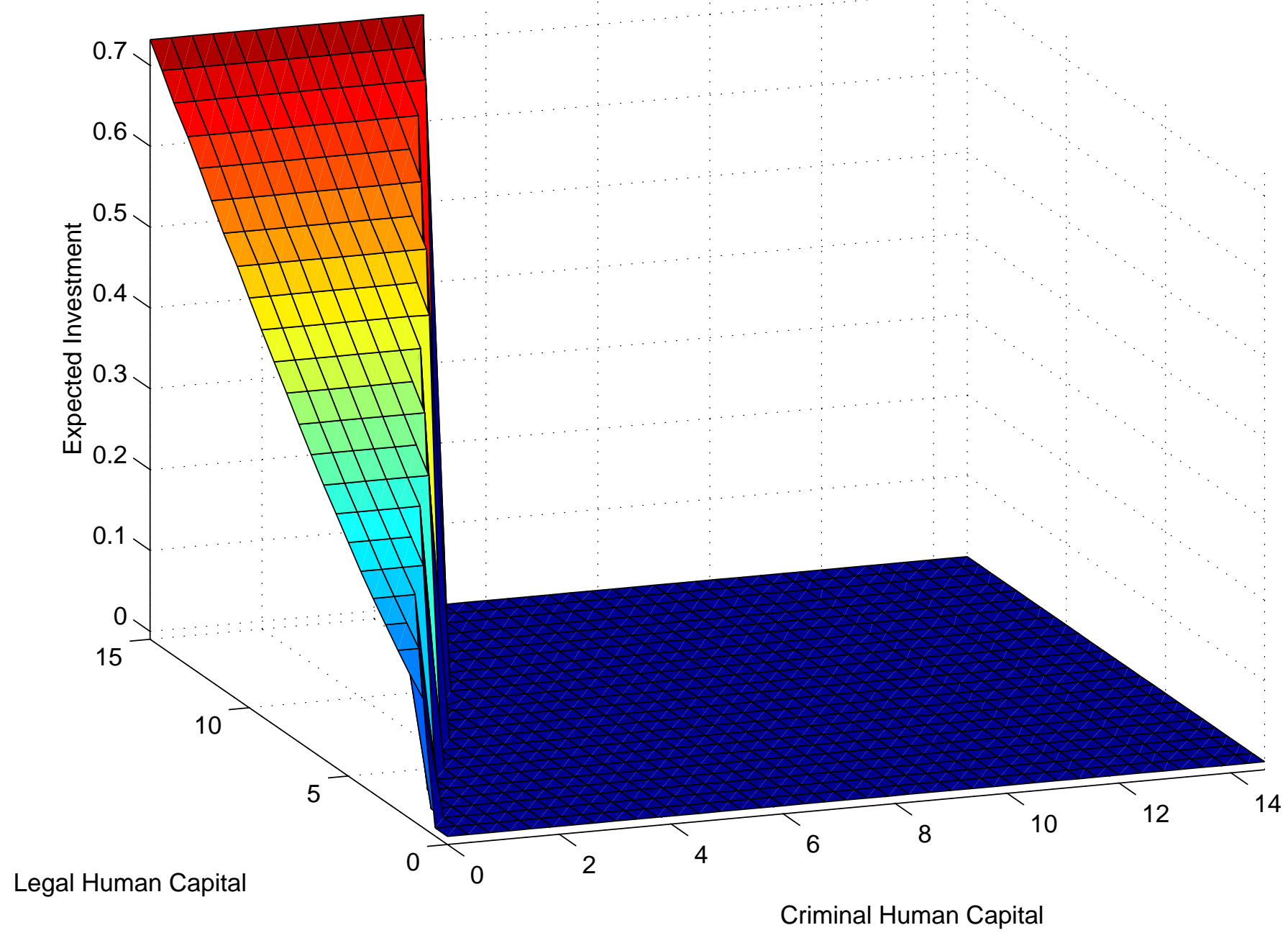


Figure 5B: Investment Policy $\operatorname{Std}(\epsilon)=0.3, \operatorname{Std}(\mu)=0.1$

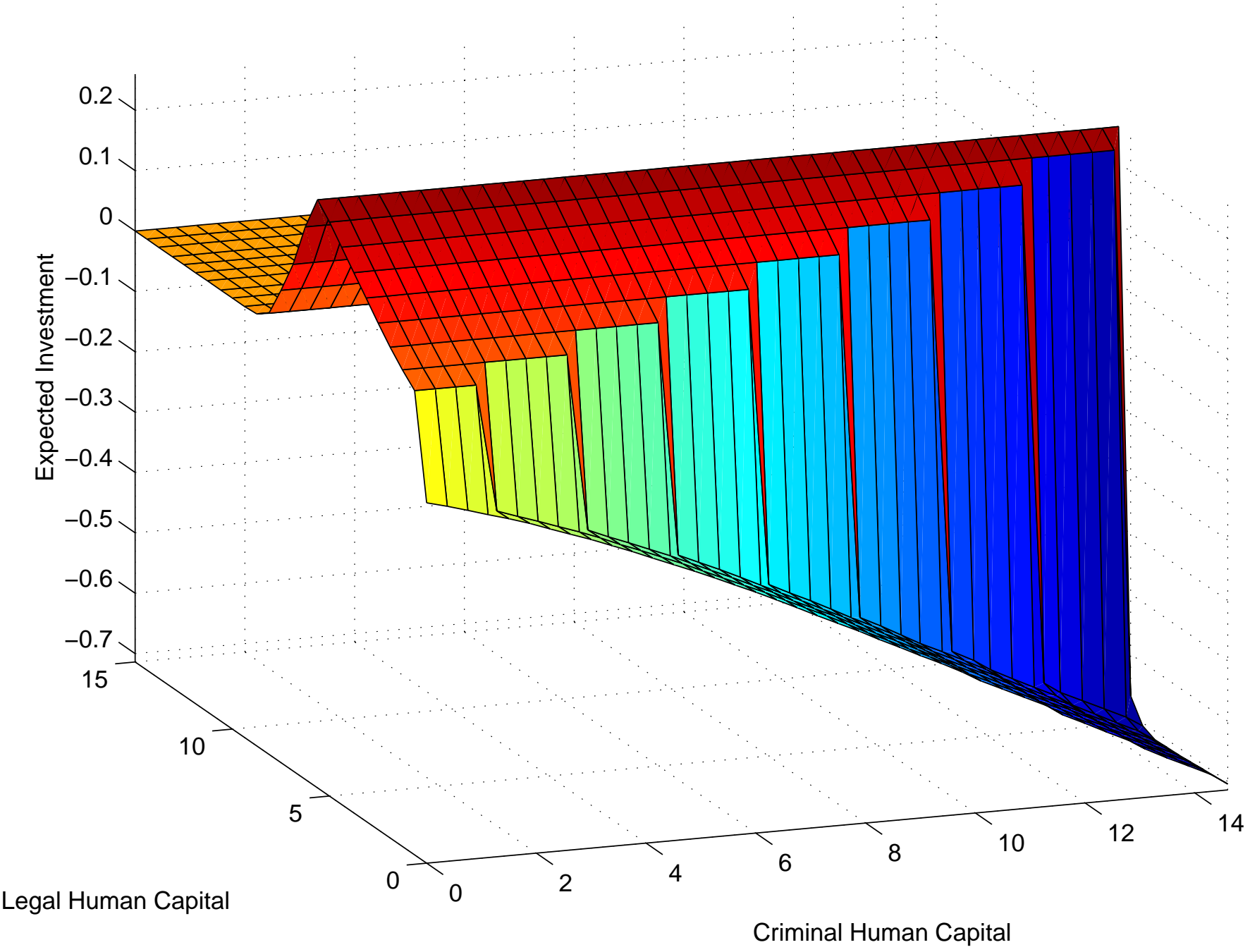


Figure 6: Recession in Legal Sector (Periods 2-6)

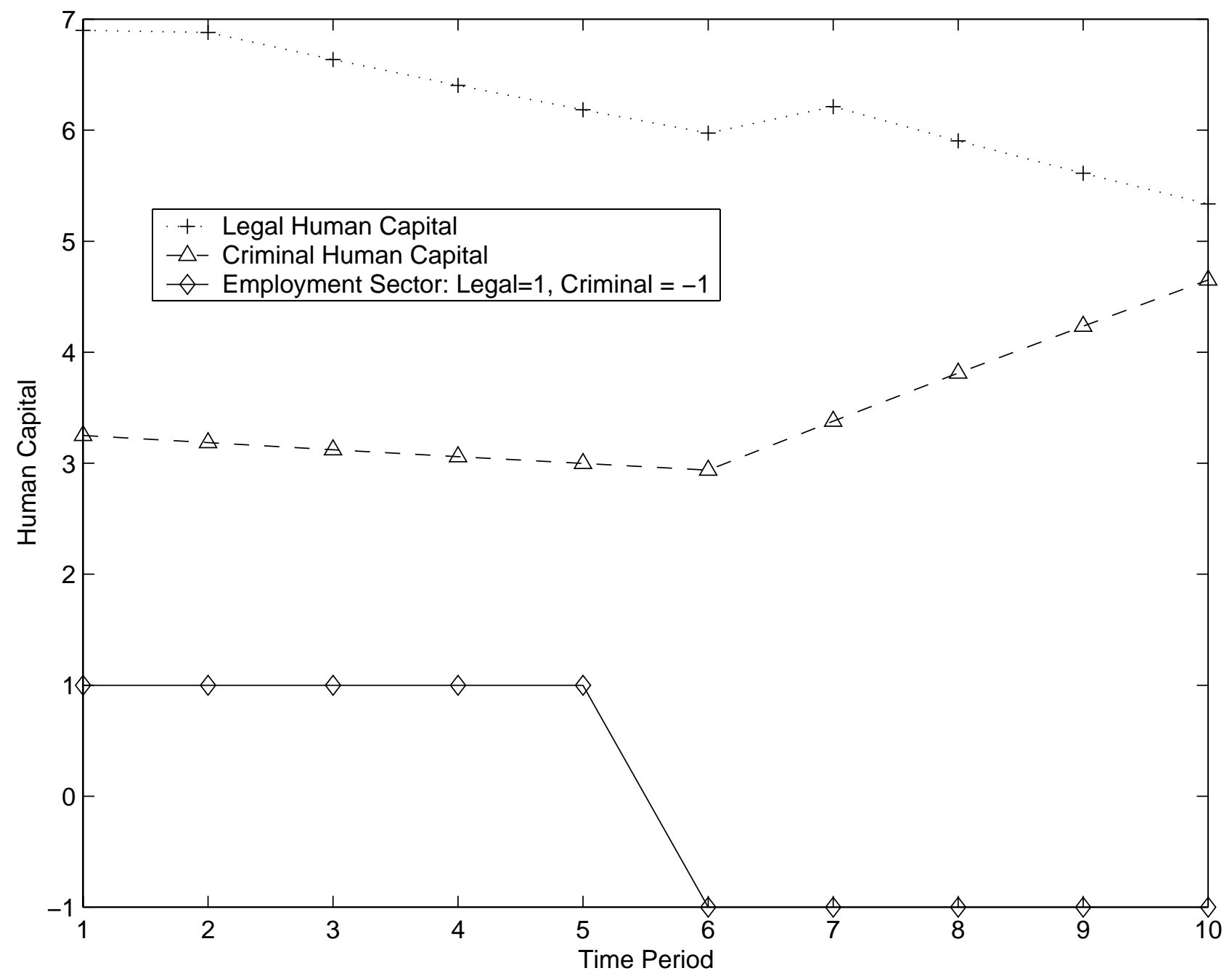


Figure 7A: Strong Criminal Neighborhood Effect $(\Psi=2, \Omega=0, \lambda=0.1$ )

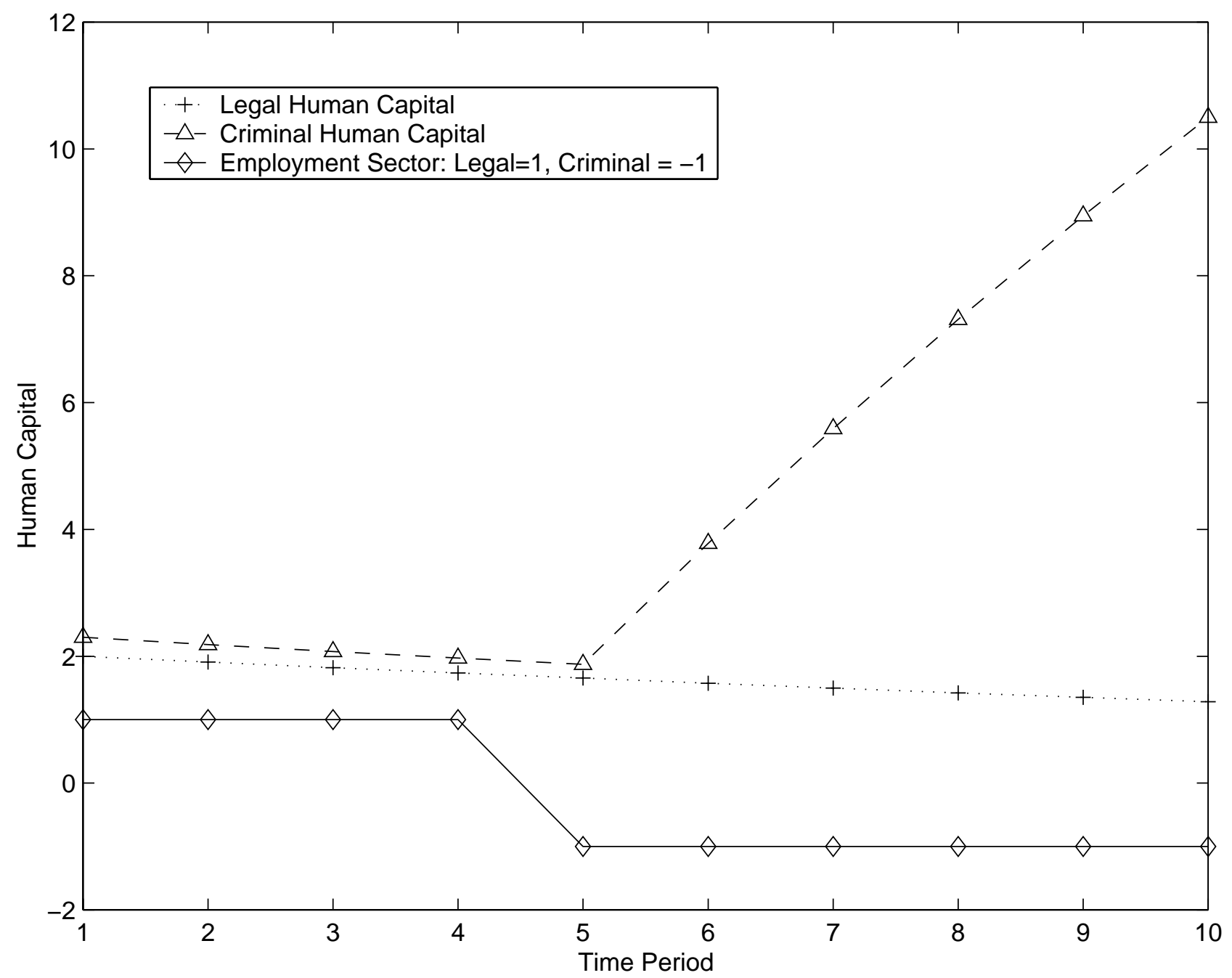


Figure 7B: No Criminal Neighborhood Effect $(\Psi=0.1, \Omega=0.2, \lambda=2$ )

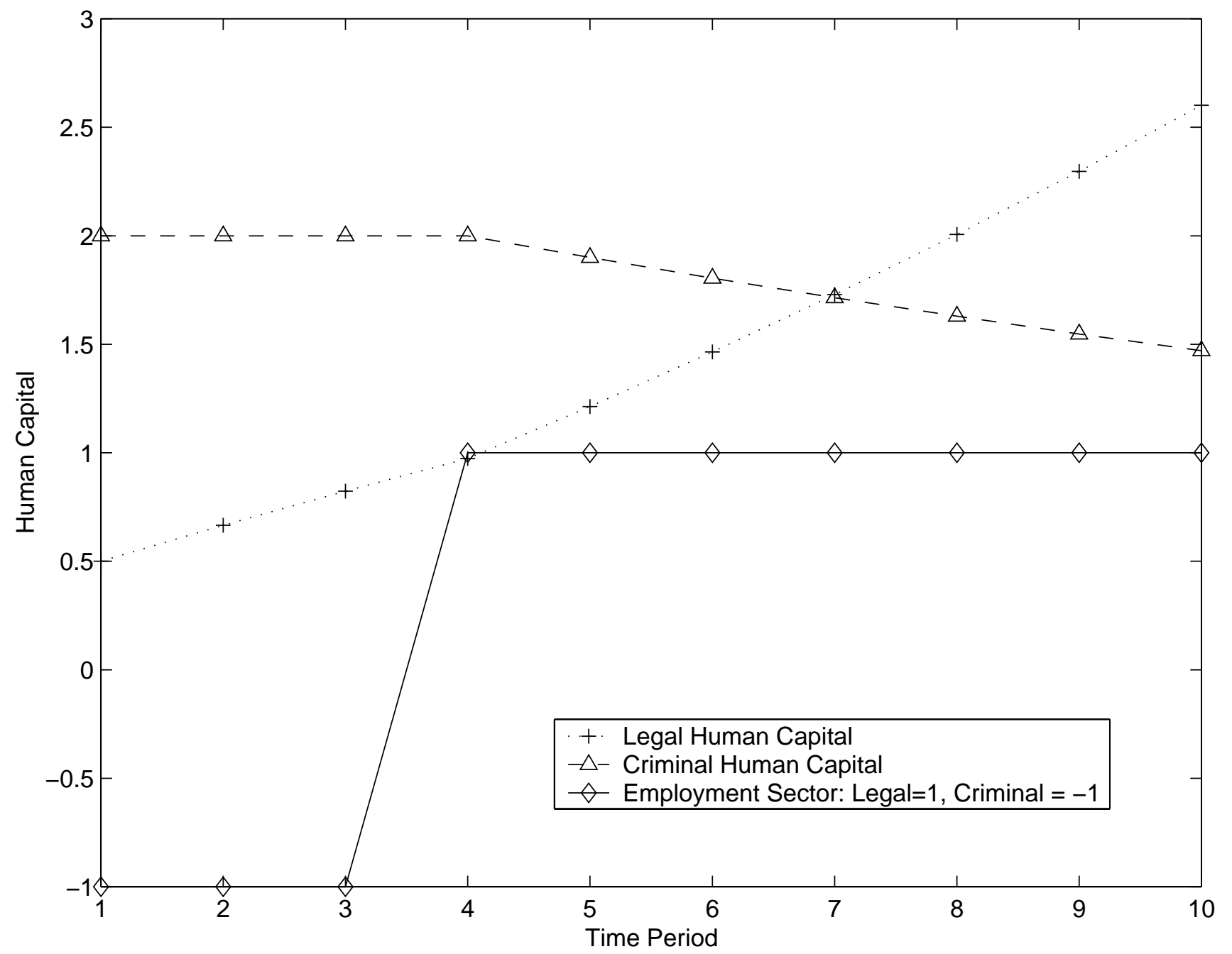


Figure 8A: No Imprisonment

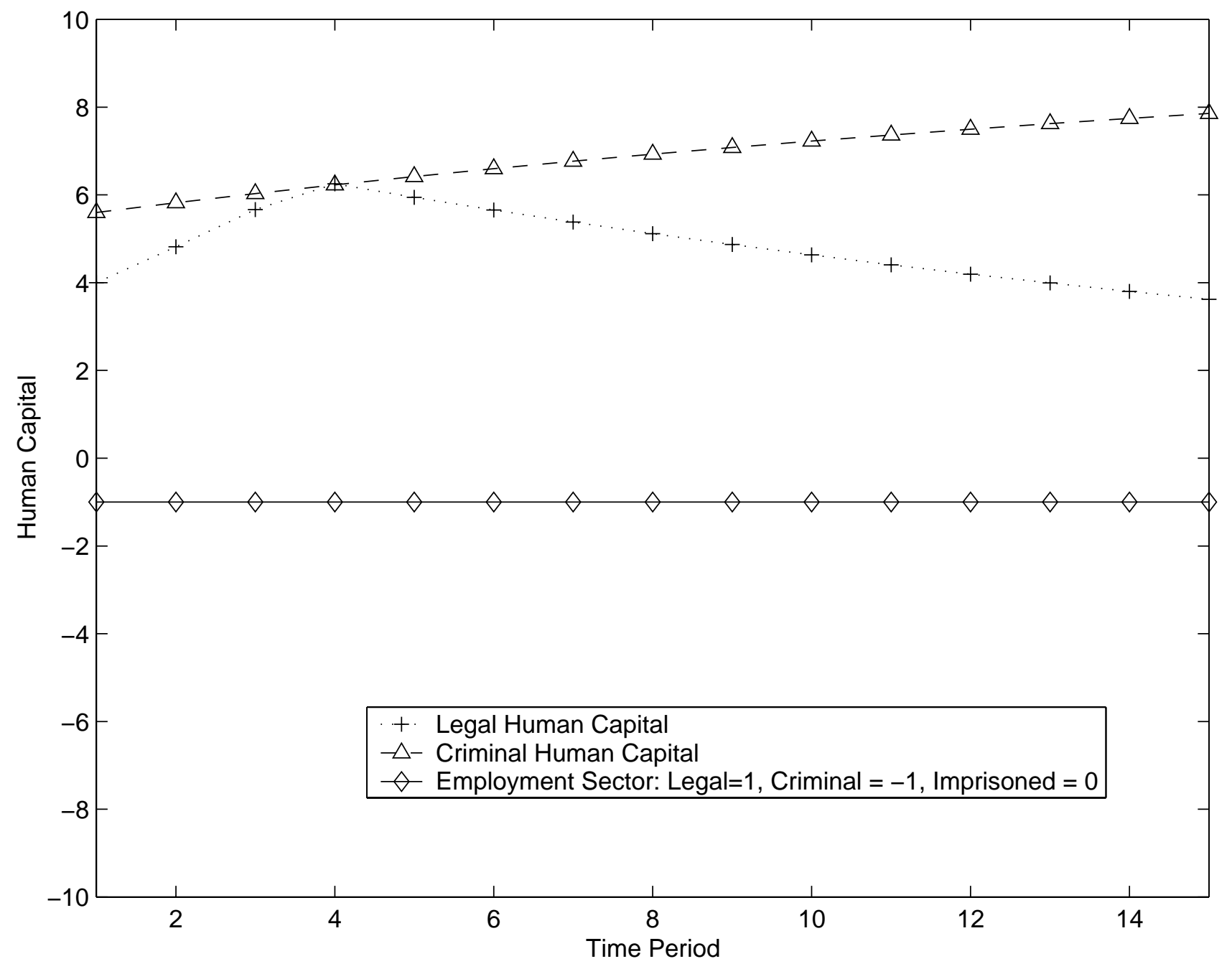


Figure 8B: Imprisonment (Periods 2-6), No Rehabilitation

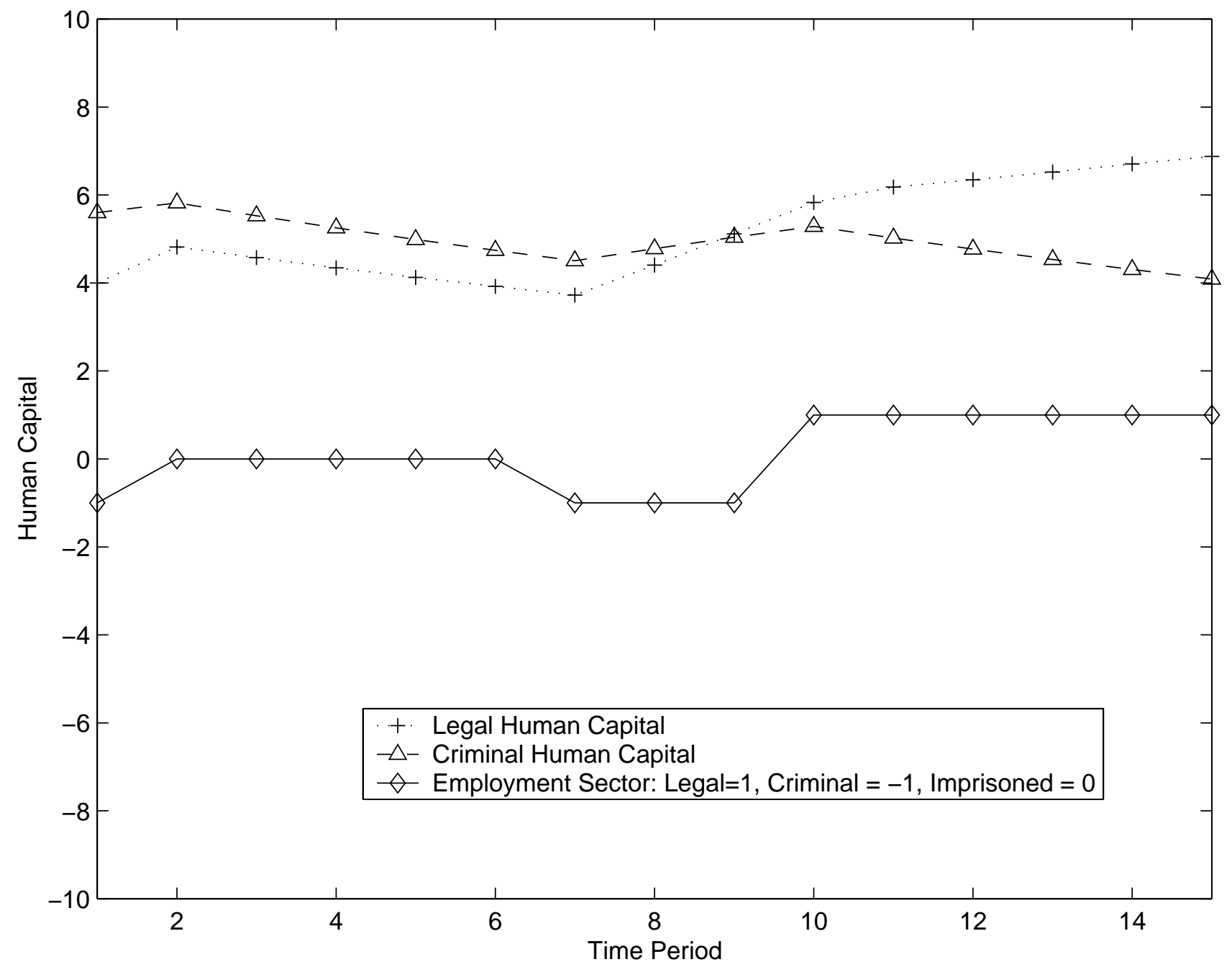


Figure 8C: Imprisonment (Periods 2-6), Prison Culture

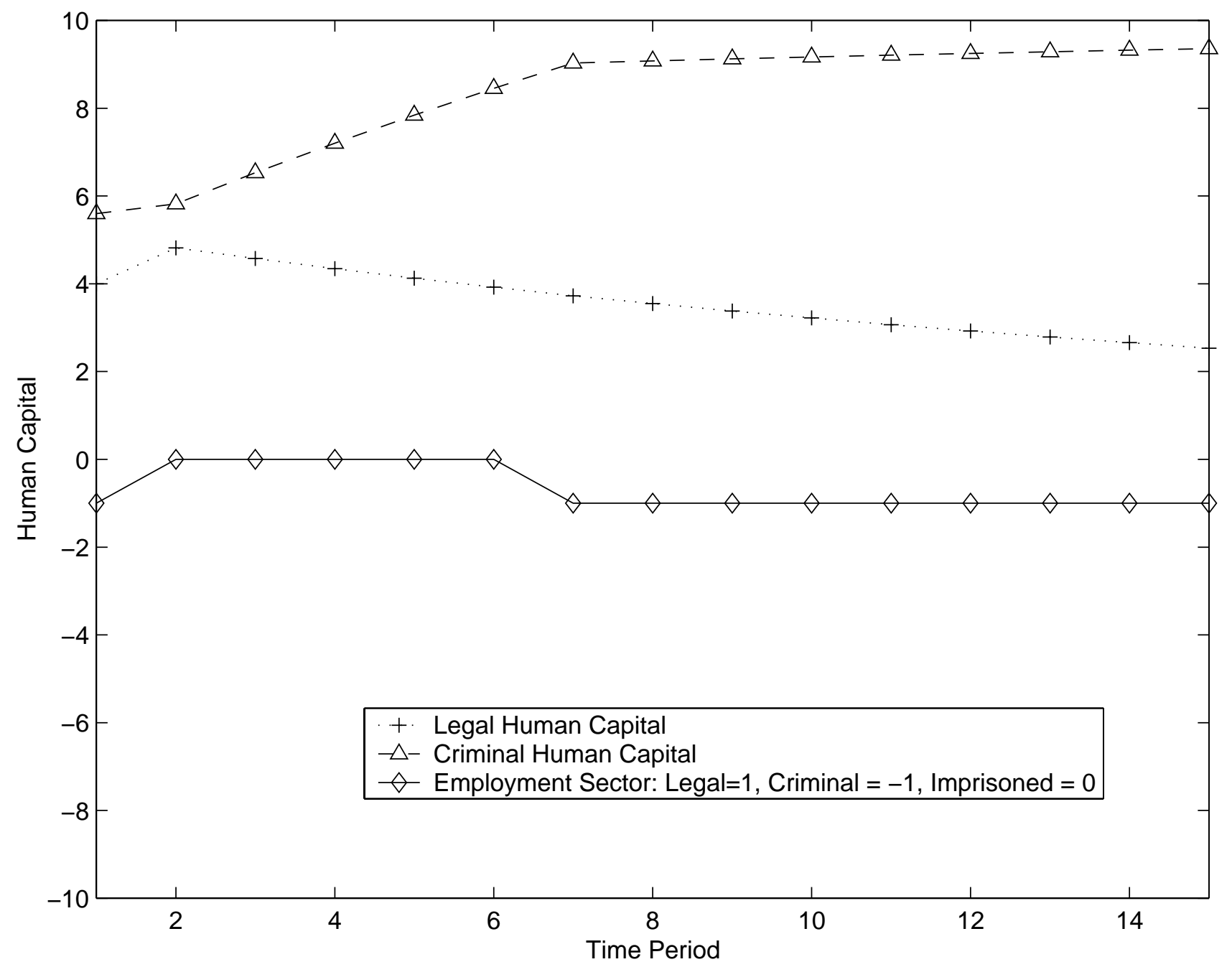


Figure 8D: Imprisonment (Periods 2-6), Rehabilitation

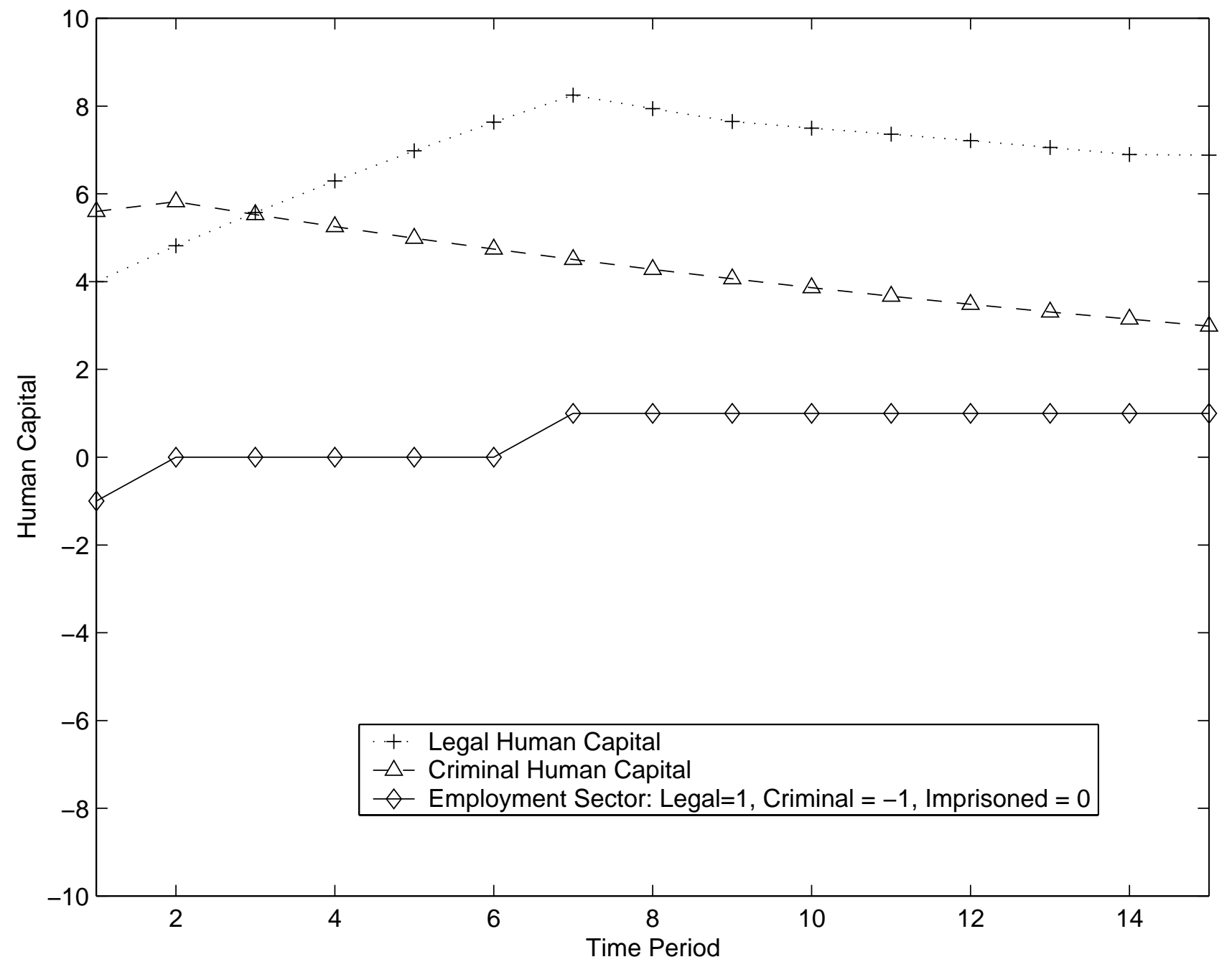


Figure 9A: Low Level of Deterrence $r^{c}=0.1$

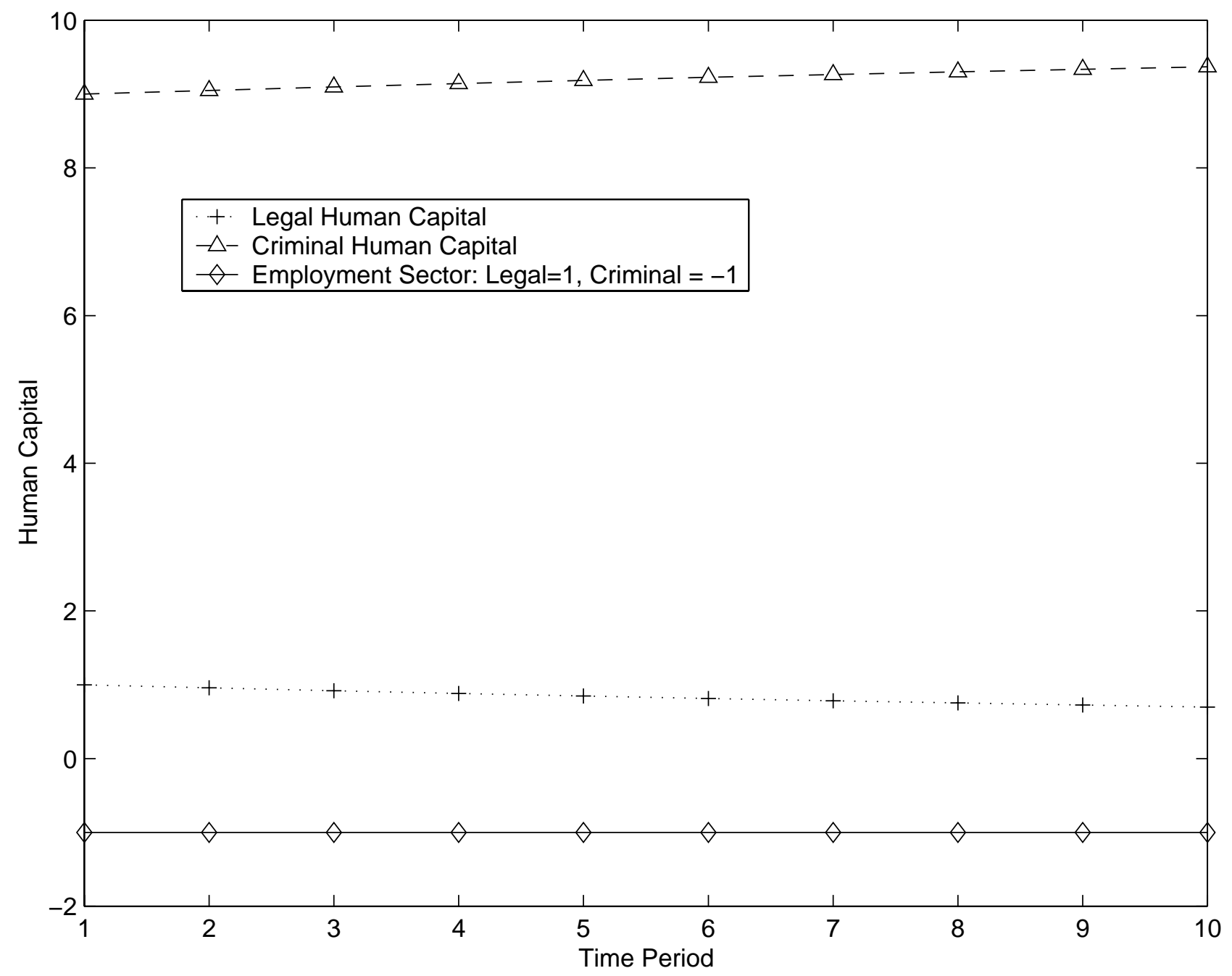


Figure 9B: High Level of Deterrence $\left(r^{c}=0.02, \operatorname{Std}(\epsilon)=0.01\right)$

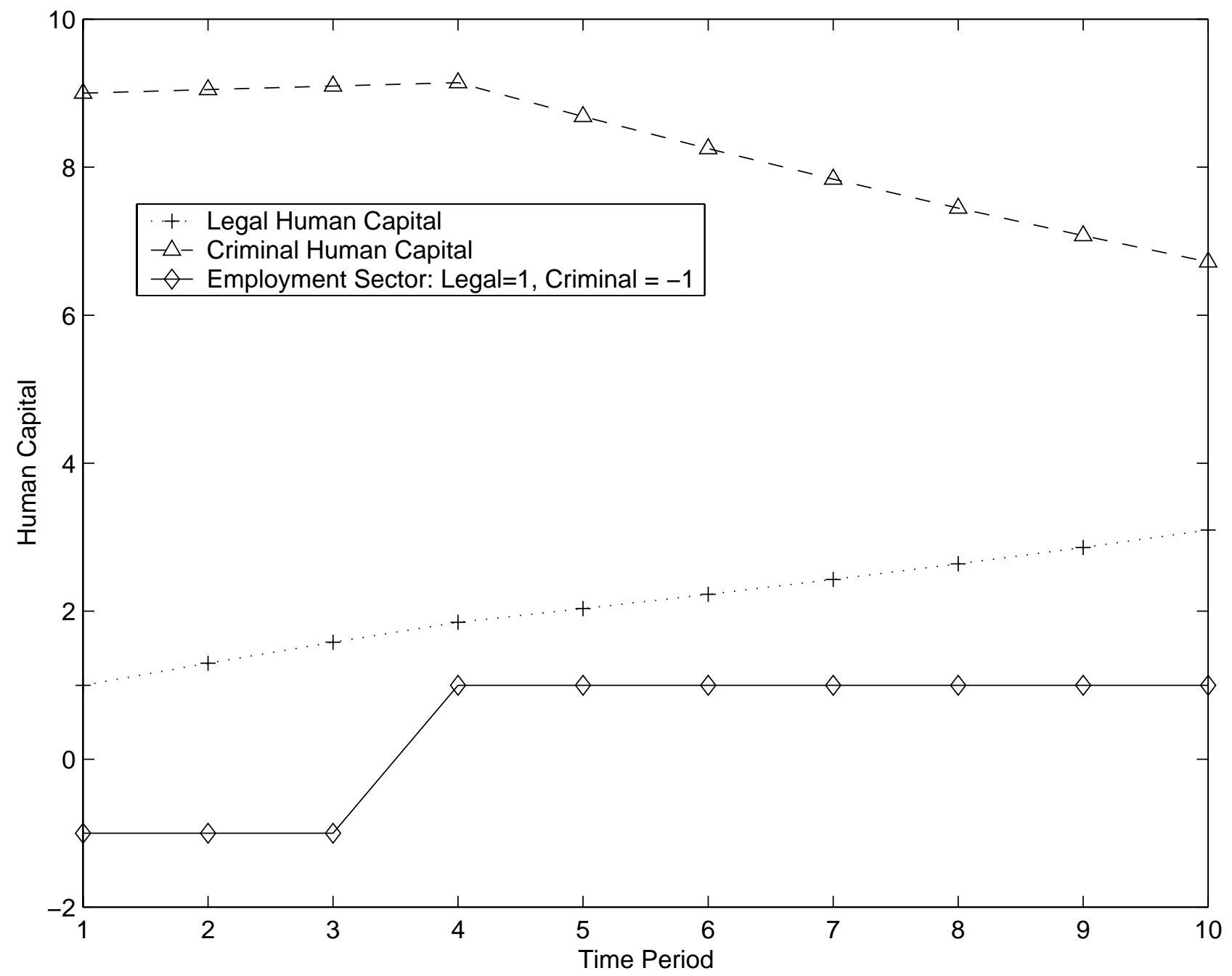


Figure 10: Increased Risk Aversion in Time Period 5

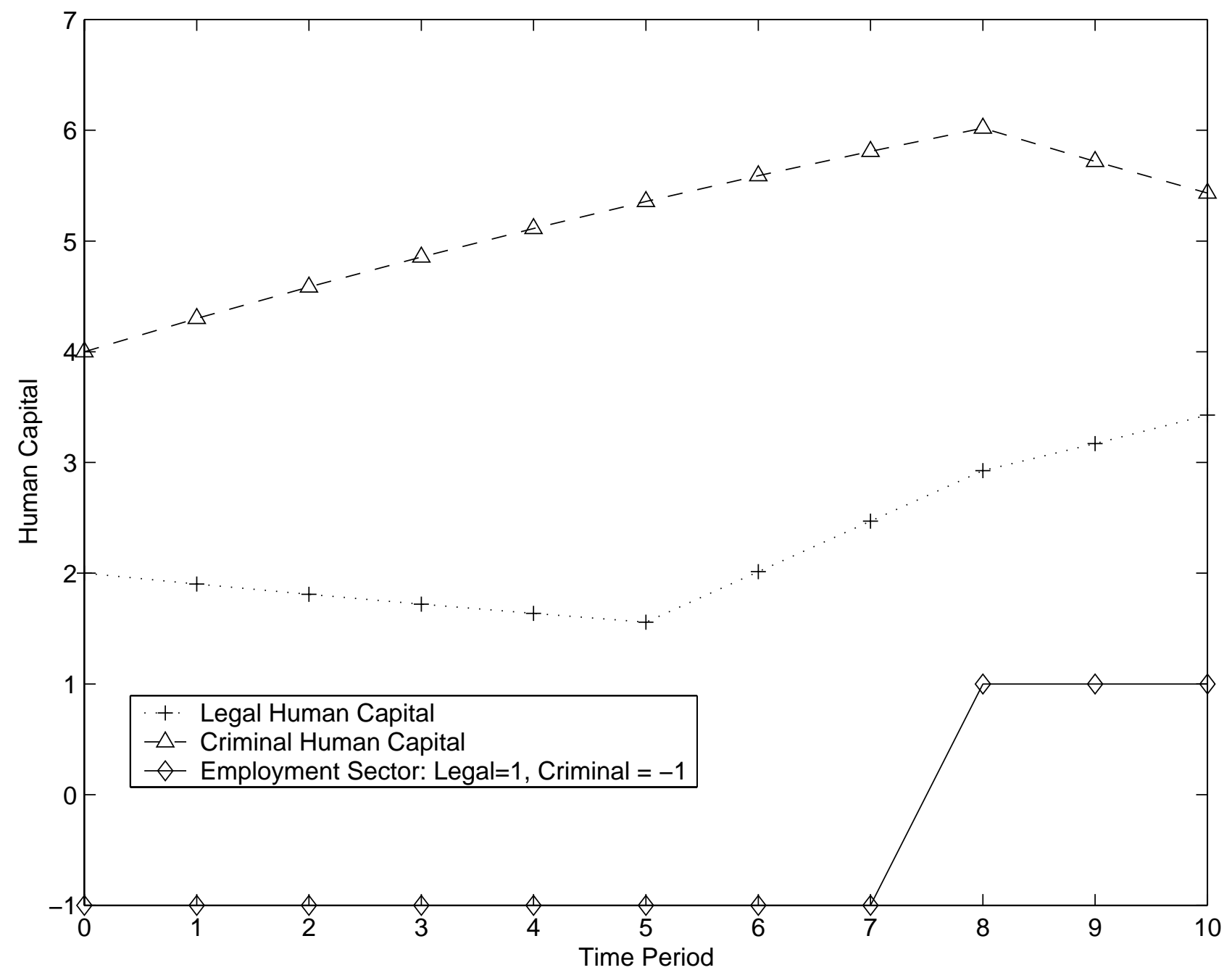


Figure 11: Change in Discount Rate

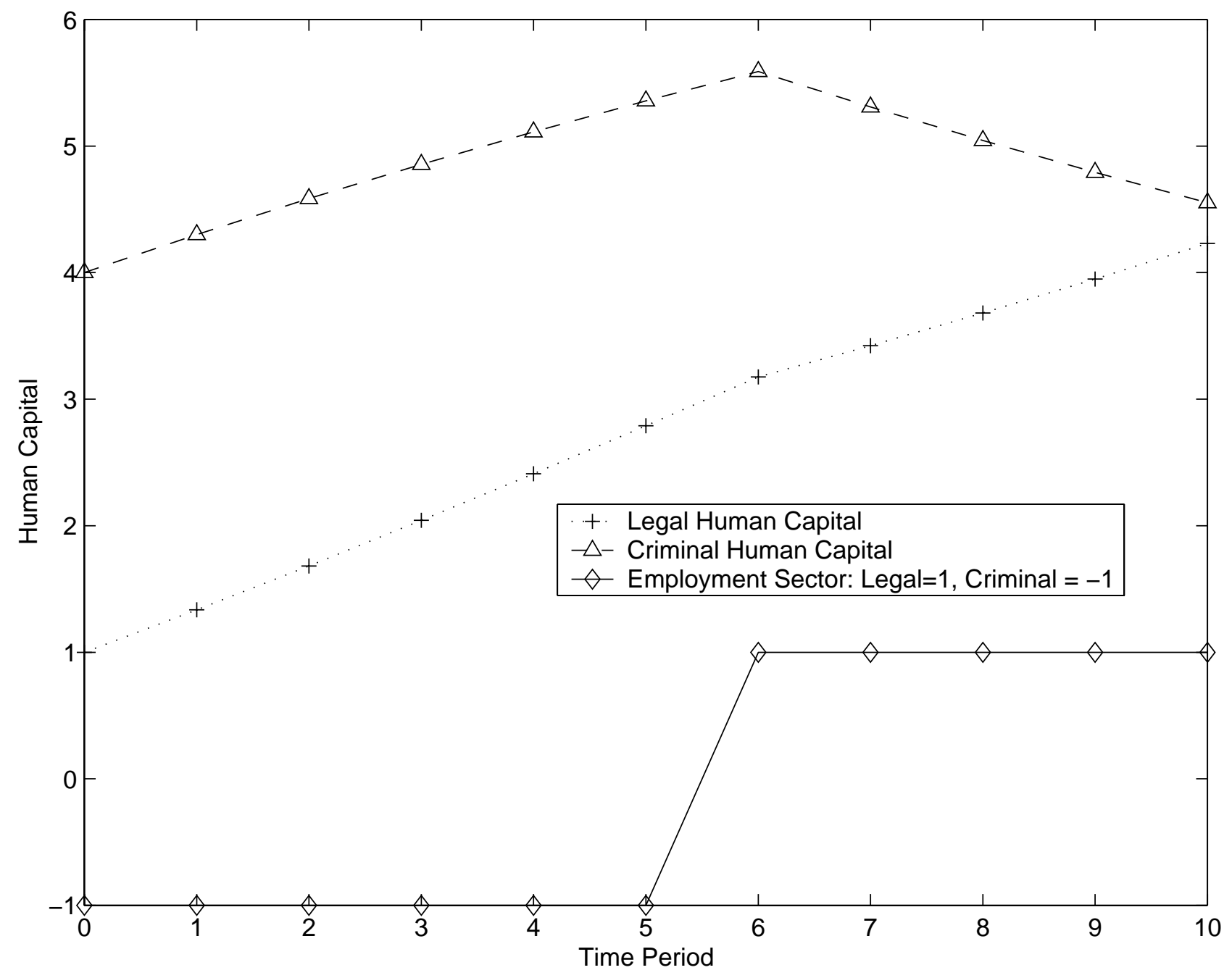




\section{References}

Becker, Gary S., Accounting for Tastes, Cambridge, MA: Harvard University Press, 1996.

Becker, Gary S., Human Capital: A Theoretical and Empirical Analysis with Special Reference to Education, Third Edition. Chicago: University of Chicago Press, 1993.

Becker, Gary S., "A Note on Restaurant Pricing and Other Examples of Social Influence on Price," The Journal of Political Economy, 1991, 99 (5): 1109 - 1116.

Becker, Gary S., "Crime and Punishment: An Economic Approach," Journal of Political Economy, 1968, 76:169-217.

Becker, Gary, Michael Grossman and Kevin M. Murphy, "Rational Addiction and the Effect of Price on Consumption," The American Economic Review Papers and Proceedings, May, 1991, 237-241.

Becker, Gary S., and C.B. Mulligan, "The Endogenous Determination of Time Preference," Quarterly Journal of Economics, 1997, 112:729 - 758.

Becker, Gary S. and K. M. Murphy, “A Theory of Rational Addiction,” Journal of Political Economy, 1988, 96: 675 - 700.

Ben-Porath, Yoram, "The Production of Human Capital and the Life Cycle of Earnings," Journal of Political Economy, 1967, 75(4): 352-65.

Block, M. and M. Heineke, "A Labor Theoretic Analysis of the Criminal Choice," The American Economic Review, 1975, 314-25.

California Department of Corrections, Program Planning for the 1978 - 1979 Fiscal Year, 4 Volumes, prepared at the request of the Joint Legislative Budget Committee of the California State Legislature. Sacramento, 1978.

Coleman, James S., Foundations of Social Theory, Cambridge, MA: Harvard University Press, 1990.

Corman, Hope and H. Naci Mocan, "A Time Series Analysis of Crime, Deterrence and Drug Abuse in New York City," American Economic Review, Forthcoming.

Cornwell, Christopher and William N. Trumbull, "Estimating the Economic Model of Crime with Panel Data," Review of Economics and Statistics, Vol. 76, May 1994: pp. 360-366.

Deaton, A., Understanding Consumption, Oxford: Clarendon Press, Clarendon Lectures in Economics, 1992. 
Dilulio, John J. "Help Wanted: Economists, Crime and Public Policy," The Journal of Economic Perspectives, 1996, 10 (1): 3 - 24.

Ehrlich, Isaac. "Participation in Illegitimate Activities: A Theoretical and Empirical Investigation," Journal of Political Economy, 1973, V81, 521-565.

Flinn, Christopher. "Dynamic Models of Criminal Careers." in Blumstein, Alfred et al. eds. Criminal Careers and "Career Criminals", 1986, Washington DC: National Academy Press.

Freeman, Richard B. "Why Do So Many Young American Men Commit Crimes and What Might We Do About It?" The Journal of Economic Perspectives, 1996, 10 (1): 25 - 42.

Freeman, Richard B. and William Rodgers III, "Area Economic conditions and the Labor Market Outcomes of Young Men in the 1990s Expansion,” NBER Working Paper 7073.

Gomes, Joao, Jeremy Greenwood, and Sergio Rebelo, "Equilibrium Unemployment," mimeo University of Rochester, May 1997.

Gottfredson, Michael R. and Travis Hirschi, A General Theory of Crime, Stanford, CA: Stanford University Press. 1990.

Grogger, Jeff. "Market Wages and Youth Crime," Journal of Labor Economics, 1998, 16(4): 756-791.

Grossman, Michael. “The Human Capital Model of the Demand for Health," in, Anthony J. Culyer and Newhouse, Joseph P., eds., Handbook of Health Economics, 1997, Amsterdam: North Holland.

Grossman, Michael, "On the Concept of Health Capital and the Demand for Health," Journal of Political Economy, 1972, 80: 223 - 55.

Jianakoplos, Nancy Ammon and Alexandra Bernasek, "Are Women More Risk Averse?" Economic Inquiry, 1998, 36(4): 620-630.

Kahan, Dan M., "Social Meaning and the Economic Analysis of Crime," The Journal of Legal Studies, 1998, XXVII(2)Part 2: 609-622.

Leung, Siu Fai, “An Economic Analysis of the Age-Crime Profile," Journal of Economic Dynamics and Control, 1994, 18:481-97.

Levitt, Steven D., "Using Electoral Cycles in Police Hiring to Estimate the Effect of Police on Crime," American Economic Review, 1997, 87(3): 270-290. 
Lochner, Lance, "Education, Work, and Crime: Theory and Evidence," University of Rochester, Working Paper No. 465, 1999.

Myers, Samuel L. Jr., "Estimating the Economic Model of Crime: Employment Versus Punishment Effects," Quarterly Journal of Economics, 1983, 157-166.

Mocan, H. Naci and Daniel I. Rees, "Economic Conditions, Deterrence and Juvenile Crime: Evidence From Micro Data,” NBER Working Paper No. 7405, 1999.

Palsson, Anne-Marie, "Does the Degree of Relative Risk Aversion Vary With Household Characteristics?" Journal of Economics Psychology, 1996, 17(6): 771-787.

Pindyck, Robert S., "Risk Aversion and Determinants of Stock Market Behavior," The Review of Economics and Statistics, 1988, 70(2): 183-190.

Schmidt, Peter and Ann Dryden Witte, An Economic Analysis of Crime and Justice: Theory, Methods and Applications, 1984, Orlando, Florida: Academic Press.

Stokey, Nancy L., Lucas, Robert E., with Edward C. Prescott, Recursive Methods in Economic Dynamics, Cambridge, Massachusetts: Harvard University Press, 1989.

Szpiro, George G., "Measuring Risk Aversion: An Alternative Approach," The Review of Economics and Statistics, 1986, 68(1): 156-159.

Tauchen, Helen, Ann Dryden Witte and Harriet Griesinger, "Criminal Deterrence: Revisiting the Issue with a Birth Cohort," The Review of Economics and Statistic, 1994, LXXVI(3): $399-412$.

Wilson, James Q., "Culture, Incentives, and the Underclass." in Arron, Henry J., Thomas E. Mann, and Timothy Taylor, eds., Values and Public Policy. Washington, D.C.: Brookings Institution, 1994, pp. 54 - 80.

Witte, Ann Dryden, "Estimating the Economic Model for Crime with Individual Data."Quarterly Journal of Economics, February 1980, 57-84.

Witte, Ann Dryden, "Estimating the Economic Model of Crime: A Reply," Quarterly Journal of Economics, 1983, 98 (1): $167-176$. 